\title{
Review and Selection Strategy for High-Accuracy Modeling of PWM Converters in DCM
}

\author{
Yu-Jun Mao, ${ }^{1}$ Chi-Seng Lam $\mathbb{D}^{1},{ }^{1}$ Sai-Weng Sin, ${ }^{1,2}$ Man-Chung Wong, ${ }^{1,2}$ \\ and Rui Paulo Martins $\mathbb{I I}^{1,2,3}$ \\ ${ }^{1}$ State Key Laboratory of Analog and Mixed-Signal VLSI, University of Macau, Macau 999078, China \\ ${ }^{2}$ Department of Electrical and Computer Engineering, Faculty of Science and Technology, University of Macau, \\ Macau 999078, China \\ ${ }^{3}$ On Leave from Instituto Superior Técnico, Universidade de Lisboa, Lisbon 1649-004, Portugal \\ Correspondence should be addressed to Chi-Seng Lam; cslam@umac.mo
}

Received 1 June 2018; Accepted 18 September 2018; Published 28 October 2018

Academic Editor: Luigi Piegari

Copyright (C) 2018 Yu-Jun Mao et al. This is an open access article distributed under the Creative Commons Attribution License, which permits unrestricted use, distribution, and reproduction in any medium, provided the original work is properly cited.

\begin{abstract}
Among various modeling methods for DC-DC converters introduced in the past two decades, the state-space averaging (SSA) and the circuit averaging (CA) are the most general and popular exhibiting high accuracy. However, their deduction approaches are not entirely equivalent since they incorporate different averaging processes, thus yielding different small signal transfer functions even under identical operating conditions. Some research studies claimed that the improved SSA can obtain the highest accuracy among all the modeling methods, but this paper discovers and clearly verifies that this is not the case. In this paper, we first review and study these two modeling methods for various DC-DC converters operating in the discontinuous conduction mode (DCM). We also streamline the general model-deriving processes for DC-DC converters, and test and compare the accuracy of these two methods under various conditions. Finally, we provide a selection strategy for a highaccuracy modeling method for different DC-DC converters operating in DCM and verified by simulations, which revealed necessary and beneficial for designing a more accurate DCM closed-loop controller for DC-DC converters, thus achieving better stability and transient response.
\end{abstract}

\section{Introduction}

A PWM DC-DC converter operates either in the continuous conduction mode (CCM) or in the discontinuous conduction mode (DCM). For small inductances or light loads, DCM operation is occasionally unavoidable in DCDC converters, their design being intentionally in DCM to reduce both the inductor's size and the switching frequency. Then, it is necessary to develop a modeling analysis for the DC-DC converter operation in DCM to design a closed-loop controller. In previous works [1-22], various small signal modeling methods of PWM DC-DC converters in CCM and DCM are proposed, where different modeling methods provide either an analytical equation or an equivalent circuit and can be categorized as reduced-order or full-order models, as summarized in Table 1.

Among these small signal modeling methods, the improved state-space averaging (SSA) and the circuit averaging (CA) are the latest to present, with high accuracy, an analytical equation, and an equivalent circuit, respectively. The improved SSA method [6] claims that it has the highest accuracy among all the other modeling methods and can be applied to any circuit composed by inductors and capacitors. But, this conclusion is only proven and verified in a boost converter under specific operating conditions [6]. Besides, this may not hold in other DC-DC converters and under different operating conditions. Moreover, Zeng et al. [13] used the CA method from [5] to deduce the small signal model of a KY converter, but when applying the improved 
TABLE 1: Summary of small signal modeling methods.

\begin{tabular}{lcc}
\hline Method name & Order & Model type \\
\hline Conventional state-space averaging (SSA) [1] & Reduced order (low accuracy) & Analytical equation \\
Converter cell [2] & Reduced order (low accuracy) & Equivalent circuit \\
Full-order SSA [3, 8, 11, 12, 20] & Full order (high accuracy) & Analytical equation \\
Circuit averaging (CA) $[4,5,8-10,13,14,17-19,21,22]$ & Full order (high accuracy) & Equivalent circuit \\
Improved SSA [6, $7,15,16]$ & Full order (high accuracy) & Analytical equation \\
\hline
\end{tabular}

SSA method to the same case, the CA method yields a better modeling accuracy under some conditions that are discussed in this paper. Contradictions met in CA and SSA methods motivate further analysis and retesting their accuracy in various DC-DC converters under different operating conditions in DCM, in order to derive a selection criterion that allows higher accuracy in the small signal modeling method.

Also, the rather complicated (and not general) original derivation processes of the CA and the improved SSA methods, in which the whole small signal model derivation process should be repeated whenever the DC-DC circuit topology changes, whenever the DC-DC circuit topology changes, leads to unnecessary and time-consuming efforts. Then, another motivation for this paper is to generalize the whole derivation process to attain a general and intuitive model-deriving solution.

The main contributions of this paper are as follows:

(1) To propose and deduct a general and intuitive derivation process of the improved SSA and CA modeling methods for different DC-DC converters, such that their corresponding DCM small signal models can be easily determined.

(2) To study, retest, and compare, through simulations, the accuracy of the improved SSA and CA modeling methods for various DC-DC converters under different operating conditions. Since most of the previous works are either based on the improved SSA or CA, they lack a detailed comparison among them.

(3) To propose a selection strategy of the DCM small signal modeling method in order to obtain high accuracy for different DC-DC converters under different operating conditions.

This paper contributes significantly to the design of a stable and fast transient response DCM closed-loop controller for different DC-DC converters. Section 2 presents the DC analysis of different DC-DC converters in DCM. Section 3 introduces two small signal relationship calculation methods based on the large-signal equation. Section 4 discusses the general DCM large-signal and small signal modeling deduction based on the improved SSA method applied to different DC-DC converters. Then, Section 5 determines the general DCM large-signal and small signal modeling deduction based on the CA method. Section 6 compares the simulation results of the small signal modeling obtained through the improved SSA and the CA methods. Section 7 presents a selection strategy of the DCM small signal modeling for different DC-DC converters. Finally, the conclusions are drawn in Section 8.

\section{DC Analysis of DC-DC Converters in DCM}

In the discussion hereafter, if we use the capital letter $X$ to denote the averaged value of a specific variable in one switching frequency (DC value), then the lowercase letter $x$ denotes its large-signal value and $\hat{x}$ denotes its small signal value. The relationship between these three variables is [10]

$$
x=X+\widehat{x}
$$

2.1. DCM Operation. The DCM operation of the DC-DC converters consists of three intervals. Here, we use $D_{1}, D_{2}$, and $D_{3}$ to denote the duty ratio of each interval, respectively, and $T_{\mathrm{s}}$ denotes the switching period. Figure 1 shows the inductor current, $i_{\mathrm{L}}$, waveform of the DC-DC converters operating in DCM [10].

For a typical DC-DC converter, $i_{\mathrm{L}}$ starts to rise during the charging of the inductor $L$ and begins to drop while the $L$ is discharging. In this paper, we use $V_{\text {on }}$ (charging) and $V_{\text {off }}$ (discharging) to denote the voltage across the $L$ in the first and the second intervals, respectively. From Figure 1, we can obtain

$$
I_{\mathrm{pk}}=\frac{V_{\mathrm{on}}}{L} D_{1} T_{\mathrm{s}}
$$

where $I_{\mathrm{pk}}$ denotes the peak value of inductor current $i_{\mathrm{L}}, D_{1}$ denotes the duty ratio of charging interval, and $T_{\mathrm{s}}$ denotes the switching period. From Figure 1, the relationship between the peak value $\left(I_{\mathrm{pk}}\right)$ and average value $\left(I_{\mathrm{L}}\right)$ of the inductor current can be expressed as

$$
\frac{1}{2} I_{\mathrm{pk}}\left(D_{1}+D_{2}\right) T_{\mathrm{s}}=I_{\mathrm{L}} T_{\mathrm{s}}
$$

where $I_{\mathrm{L}}$ denotes the average value of the inductor current $i_{\mathrm{L}}$ while $T_{\mathrm{s}}$ and $D_{2}$ denotes the duty ratio of the discharging interval. From Figure 1,

$$
\frac{V_{\mathrm{on}}}{L} D_{1} T_{\mathrm{s}}=\frac{-V_{\mathrm{off}}}{L} D_{2} T_{\mathrm{s}}=I_{\mathrm{pk}} \text {. }
$$

Equation (4) yields the following

$$
D_{2}=-\frac{V_{\text {on }}}{V_{\text {off }}} D_{1} \text {, }
$$

where $V_{\text {on }}$ (charging) and $V_{\text {off }}$ (discharging) denote the voltage across the $L$ in the first and the second intervals, 


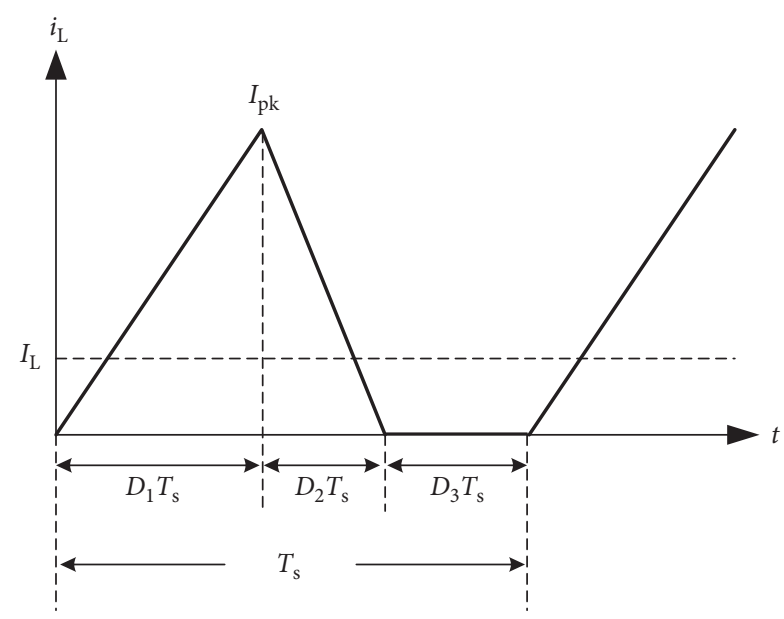

FIGURE 1: Inductor current of DC-DC converters operating in DCM.

respectively. Considering (2), (3), and (5), $I_{\mathrm{L}}$ can be expressed as

$$
I_{\mathrm{L}}=\frac{D_{1}^{2} T_{\mathrm{s}} V_{\text {on }}\left(V_{\text {off }}-V_{\text {on }}\right)}{2 L V_{\text {off }}} .
$$

\subsection{Parameters Calculation for Different DC-DC Con-} verters in DCM. Before we derive the small signal model, some DC parameters of the circuit operating in DCM need to be calculated beforehand. Figure 2 shows the four DC-DC converters that will be studied throughout this paper; they are the buck converter, the boost converter, the buck-boost converter, and the KY converter [23], where $v_{\mathrm{i}} / i_{\mathrm{i}}$ and $v_{\mathrm{o}} / i_{\mathrm{o}}$ represent the input and output voltage/current of the converter, respectively, and $L$ represents the inductor, $D$ the diode, $S$ the switch, $C$ the output capacitor, $R$ the loading, $C_{\mathrm{f}}$ the flying capacitor, $i_{\mathrm{L}}$ the inductor current, $i_{\mathrm{D}}$ the diode current, and $i_{\mathrm{S}}$ the switch current. As the equivalent series resistance (ESR) for the passive components are usually small due to high $Q$ design, which are neglected in this paper for simplification. Thus, the left-hand plane zero caused by the ESR of the output capacitor $C$ will not present in the small signal transfer functions for different DC-DC converters.

For calculating the necessary DC parameters of different DC-DC converters, we can just input different $V_{\text {on }}$ and $V_{\text {off }}$ into (5) and (6). For the buck converter, $V_{\mathrm{on}}=V_{\mathrm{i}}-V_{\mathrm{o}}$ and $V_{\text {off }}=-V_{\text {o }}$; for the boost converter, $V_{\text {on }}=V_{\mathrm{i}}$ and $V_{\text {off }}=V_{\mathrm{i}}-$ $V_{\mathrm{o}}$; for the buck-boost converter, $V_{\mathrm{on}}=V_{\mathrm{i}}$ and $V_{\text {off }}=-V_{\mathrm{o}}$, and for the KY converter, $V_{\text {on }}=2 V_{\mathrm{i}}-V_{\mathrm{o}}$ and $V_{\text {off }}=V_{\mathrm{i}}-V_{\mathrm{o}}$. On the other hand, using $M=V_{\mathrm{o}} / V_{\mathrm{i}}$ to denote the voltage gain, then $D_{2}$ and $I_{\mathrm{L}}$ can be calculated via (5) and (6), as summarized in Table 2.

For the DC relationship between $D_{1}$ and $M$, according to [4], the DC relationships among the inductor current $i_{\mathrm{L}}$, the switch current $i_{\mathrm{S}}$, and the diode current $i_{\mathrm{D}}$ are

$$
\begin{aligned}
& I_{\mathrm{S}}=\frac{D_{1}}{D_{1}+D_{2}} I_{\mathrm{L}}, \\
& I_{\mathrm{D}}=\frac{D_{2}}{D_{1}+D_{2}} I_{\mathrm{L}} .
\end{aligned}
$$

For different DC-DC converters' configurations as in Figure 2, the output current $I_{\mathrm{O}}=I_{\mathrm{L}}$ for the buck and the KY converters and $I_{\mathrm{o}}=I_{\mathrm{D}}$ for the boost and the buckboost converters. With the $D_{2}$ and $I_{\mathrm{L}}$ in Table 2 and the help of (7) and (8), the relationship between $D_{1}$ (expressed as $D_{1}^{2} T_{s} R / 2 L$ ) and $M$ can be calculated as presented in Table 2. These parameters are essential for the small-signal transfer function calculation as shown in Sections 4 and 5.

\section{Calculation of the Small-Signal Relationship with the Proposed Differentiation Method}

If $f$ is a large-signal function of some variables $x, y$, and $z$, to attain the small-signal model of these variables, we can express them as the sums of DC and small signal components [10],

$$
\begin{aligned}
& f=F+\hat{f}, \\
& x=X+\hat{x}, \\
& y=Y+\hat{y}, \\
& z=Z+\widehat{z} .
\end{aligned}
$$

By neglecting the DC terms and the high-order small signal terms, we can realize the linear approximation. During the small signal calculation, the following approximation can be used:

$$
\frac{1}{1+\widehat{x}} \approx 1-\widehat{x} .
$$

For example, the large-signal inductor current of the buck converter given by Kazimierczuk [10] is shown in (14), which can also be given by referring to the expression of $I_{\mathrm{L}}$ in Table 2 and replacing all DC quantities with large-signal quantities. The basis for this replacement is that large-signal analysis is based on DC relationship of circuit variables $[10,15,19,21]$ :

$$
i_{\mathrm{L}}=\frac{d_{1}^{2} T_{\mathrm{s}} v_{\mathrm{i}}(1-m)}{2 \mathrm{Lm}},
$$

where $m$ denotes the large-signal voltage gain and $v_{\mathrm{i}}$ denotes the small signal input voltage. Expressing the variables as the sums of DC and AC components as (9)-(12) do yield (15), after cancelling the DC components, the small signal expression of the inductor current $\hat{i}_{\mathrm{L}}$ will become (16): 


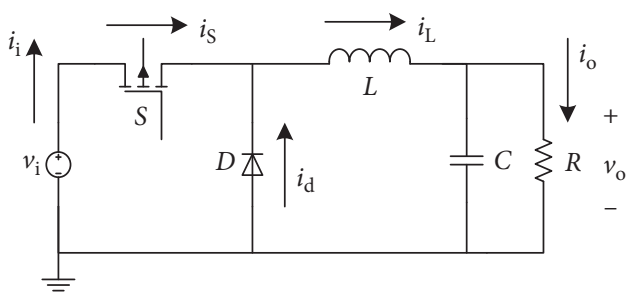

(a)

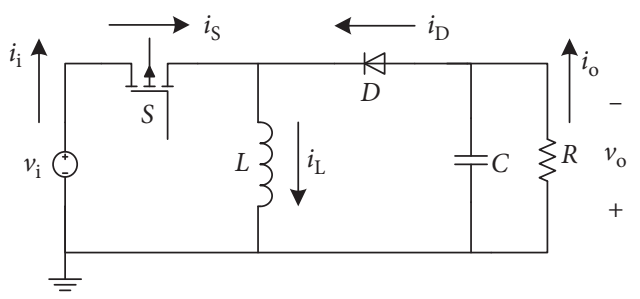

(c)

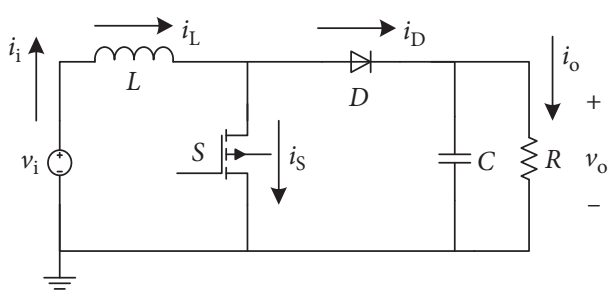

(b)

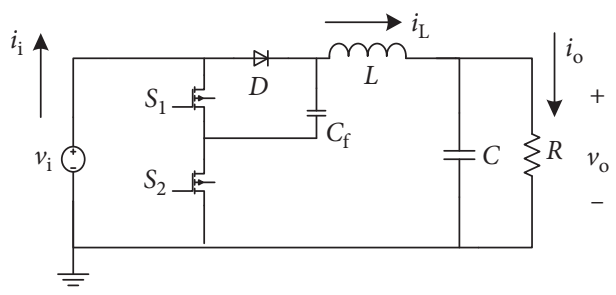

(d)

FIgURE 2: Circuit configuration of (a) buck, (b) boost, (c) buck-boost, and (d) KY converters.

TABLE 2: DC parameters for different DC-DC converters.

\begin{tabular}{lccc}
\hline DC-DC converter & $D_{2}$ & $I_{\mathrm{L}}$ & $\left(D_{1}^{2} T_{\mathrm{s}} R\right) /(2 L)$ \\
\hline Buck & $((1-M) / M) D_{1}$ & $\left(D_{1}^{2} T_{\mathrm{s}} V_{\mathrm{i}}(1-M)\right) /(2 L M)$ & $\left(M^{2} /(1-M)\right)$ \\
Boost & $(1 /(M-1)) D_{1}$ & $\left(D_{1}^{2} T_{\mathrm{s}} V_{\mathrm{i}} M\right) /(2 L(M-1))$ & $M^{2}-M$ \\
Buck-boost & $(1 / M) D_{1}$ & $\left(D_{1}^{2} T_{\mathrm{s}} V_{\mathrm{i}}(1+M)\right) /(2 L M)$ & $M^{2}$ \\
KY & $((2-M) /(M-1)) D_{1}$ & $D_{1}^{2} T_{s} V_{i}(2-M) / 2 L(M-1)$ & $(M(M-1)) /(2-M)$ \\
\hline
\end{tabular}

$$
\begin{aligned}
I_{\mathrm{L}}+\widehat{i}_{\mathrm{L}} & =\frac{\left(D_{1}+\widehat{d}_{1}\right)^{2} T_{\mathrm{s}}\left(V_{\mathrm{i}}+\widehat{v}_{\mathrm{i}}\right)(1-M-\widehat{m})}{2 L(M+\widehat{m})} \\
& \approx \frac{T_{s}\left(D_{1}^{2}+2 D_{1} \widehat{d}_{1}\right)\left(V_{\mathrm{i}}+\widehat{v}_{\mathrm{i}}\right)(1-M-\widehat{m})(1-(\widehat{m} / M))}{2 L M}, \\
\hat{i}_{\mathrm{L}} & =\frac{T_{\mathrm{s}}\left[2 D_{1} V_{\mathrm{i}}(1-M) \widehat{d}_{1}+D_{1}^{2}(1-M) \widehat{v}_{\mathrm{i}}-D_{1}^{2} V_{\mathrm{i}} \hat{m}-D_{1}^{2} V_{\mathrm{i}}(1-M)(\widehat{m} / M)\right]}{2 L M} \\
& =\frac{D_{1} T_{\mathrm{s}} V_{\mathrm{i}}(1-M)}{L M} \widehat{d}_{1}+\frac{D_{1}^{2} T_{\mathrm{s}}(1-M)}{2 L M} \widehat{v}_{\mathrm{i}}-\frac{D_{1}^{2} T_{\mathrm{s}} V_{\mathrm{i}}}{2 L M^{2}} \widehat{m} .
\end{aligned}
$$

However, the above deduction process is quite complicated and time-consuming. To simplify the analysis, we can utilize the calculation of the small signal perturbation as shown in Figure 3.

With a small variation of $\hat{x}$, the corresponding variation of $\widehat{f}$ is also very small such that the value $\widehat{f} / \widehat{x}$ is equal to the derivative of $f$ to $x$, thus yielding

$$
\widehat{f}=f_{x}^{\prime} \hat{x}+f_{y}^{\prime} \hat{y}+f_{z}^{\prime} \widehat{z}
$$

Following (17) and taking the derivative of (14) with respect to each variable, we can easily get

$$
\widehat{i}_{\mathrm{L}}=\frac{D_{1} T_{\mathrm{s}} V_{\mathrm{i}}(1-M)}{L M} \widehat{d}_{1}+\frac{D_{1}^{2} T_{\mathrm{s}}(1-M)}{2 L M} \widehat{v}_{\mathrm{i}}-\frac{D_{1}^{2} T_{\mathrm{s}} V_{\mathrm{i}}}{2 L M^{2}} \widehat{m}
$$

where the results in (16) and (18) are equivalent. In the following section, we will use the proposed differentiation method (17) to calculate the small signal relationship.

\section{Improved State-Space Averaging Method for Large-Signal and Small Signal Modeling Deduction}

In this section, the approach for deducing the DCM small signal models for different DC-DC converters by using the improved SSA method will be discussed.

4.1. General Large-Signal and Corresponding Small Signal Modeling Using the SSA Method. According to the conclusion from [10], the large-signal value relationship and the DC value relationship are identical. Then, (2) and (3) lead to the following large-signal duty ratio $d_{2}$ :

$$
d_{2}=\frac{2 L i_{\mathrm{L}}}{v_{\mathrm{on}} d_{1} T_{\mathrm{s}}}-d_{1} .
$$

By applying the SSA to the inductor voltage and using (19), we get 


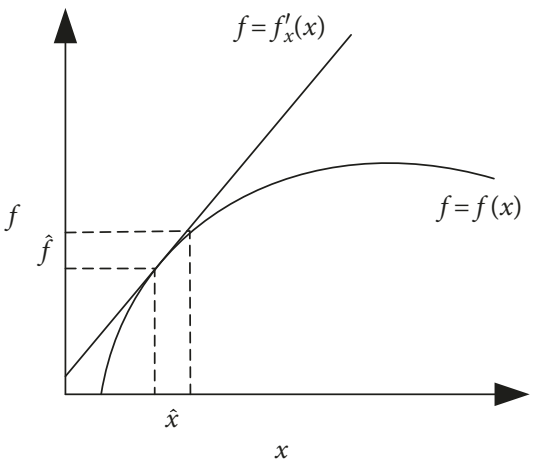

FIgURE 3: Small signal perturbation.

$$
L \frac{d i_{\mathrm{L}}}{d t}=v_{\mathrm{on}} d_{1}+v_{\mathrm{off}} d_{2}=\left(v_{\mathrm{on}}-v_{\mathrm{off}}\right) d_{1}+\frac{2 v_{\mathrm{off}} L i_{\mathrm{L}}}{v_{\mathrm{on}} d_{1} T_{\mathrm{s}}} .
$$

Taking the derivative of (20) with respect to $v_{\text {on }}, v_{\text {off }}, d_{1}$, and $i_{\mathrm{L}}$, which are variables in (20), and using (6), we will have the corresponding small signal model given by

$$
\begin{aligned}
L \frac{d \hat{i}_{\mathrm{L}}}{d t}= & \left(\frac{2 V_{\text {on }}-V_{\text {off }}}{V_{\text {on }}} D_{1}\right) \widehat{v}_{\text {on }}+\left(-\frac{V_{\text {on }}}{V_{\text {off }}} D_{1}\right) \widehat{v}_{\text {off }} \\
& +2\left(V_{\text {on }}-V_{\text {off }}\right) \hat{d}_{1}+\left(\frac{V_{\text {off }}-V_{\text {on }}}{I_{\mathrm{L}}} D_{1}\right) \hat{i}_{\mathrm{L}} .
\end{aligned}
$$

Then, using the SSA to the capacitor current yields

$$
C \frac{d u_{\mathrm{C}}}{d t}=i_{\mathrm{o}}-\frac{u_{\mathrm{C}}}{R}
$$

If $i_{\mathrm{o}}=i_{\mathrm{L}}$, and taking the derivative of (22), the corresponding small signal model becomes

$$
C \frac{d \widehat{u}_{\mathrm{C}}}{d t}=\widehat{i}_{\mathrm{L}}-\frac{\widehat{u}_{\mathrm{C}}}{R}
$$

If $i_{\mathrm{o}}=i_{\mathrm{D}}$, then (8), (19), and (22) lead to

$$
C \frac{d u_{\mathrm{C}}}{d t}=i_{\mathrm{L}}-\frac{d_{1}^{2} T_{\mathrm{s}} v_{\mathrm{on}}}{2 L}-\frac{u_{\mathrm{C}}}{R}
$$

Finally, taking the derivative of (24), we obtain the corresponding small signal model as follows:

$$
C \frac{d \widehat{u}_{\mathrm{C}}}{d t}=\widehat{i}_{\mathrm{L}}-\frac{D_{1} T_{\mathrm{s}} V_{\text {on }}}{L} \widehat{d}_{1}-\frac{D_{1}^{2} T_{\mathrm{s}}}{2 L} \widehat{v}_{\text {on }}-\frac{\widehat{u}_{\mathrm{C}}}{R},
$$

where (21), (23), and (25) are the three general equations for deducing the DCM small signal models of different DC-DC converters. Then, after input, the values of the inductor voltage drops during the charging $\left(V_{\text {on }}\right)$ and discharging $\left(V_{\text {off }}\right)$ cycles, as well as the DC parameters of each DC-DC converter from Table 2, into (21), (23), and (25), and the corresponding DCM small signal models can be deduced easily, as detailed next.

4.2. Buck Converter Small Signal Transfer Function. For the buck converter, $V_{\mathrm{on}}=V_{\mathrm{i}}-V_{\mathrm{o}}, V_{\mathrm{off}}=-V_{\mathrm{o}}$, and $i_{\mathrm{o}}=i_{\mathrm{L}}$. Besides, Table 2 gives $I_{\mathrm{L}}=\left(D_{1}^{2} T_{\mathrm{s}} V_{\mathrm{i}}(1-M)\right) /(2 L M)$ and $\left(D_{1}^{2} T_{s} R\right) /(2 L)=\left(M^{2}\right) /(1-M)$, and substituting them into (21) and (23), gives

$$
\begin{aligned}
L \frac{d \widehat{i}_{\mathrm{L}}}{d t}= & \left(\frac{2 V_{\mathrm{i}}-V_{\mathrm{o}}}{V_{\mathrm{i}}-V_{\mathrm{o}}} D_{1}\right)\left(\widehat{v}_{\mathrm{i}}-\widehat{v}_{\mathrm{o}}\right) \\
& -\left(\frac{V_{\mathrm{i}}-V_{\mathrm{o}}}{V_{\mathrm{o}}} D_{1}\right) \widehat{v}_{\mathrm{o}}+2 V_{\mathrm{i}} \widehat{d}_{1}-\frac{V_{\mathrm{i}}}{I_{\mathrm{L}}} D_{1} \widehat{i}_{\mathrm{L}}, \\
C \frac{d \widehat{u}_{\mathrm{C}}}{d t}= & \widehat{i}_{\mathrm{L}}-\frac{\widehat{u}_{\mathrm{C}}}{R} .
\end{aligned}
$$

Let $\widehat{v}_{i}=0$, then (26) becomes

$$
\left(s L+\frac{2 L M}{D_{1} T_{\mathrm{s}}(1-M)}\right) \widehat{i}_{\mathrm{L}}=\frac{1}{M^{2}-M} D_{1} \widehat{v}_{\mathrm{o}}+2 V_{\mathrm{i}} \widehat{d}_{1} .
$$

Further, if $u_{\mathrm{c}}=v_{\mathrm{o}}$, then (27) will be

$$
\left(s C+\frac{1}{R}\right) \widehat{v}_{\mathrm{O}}=\widehat{i}_{\mathrm{L}}
$$

Considering (28) and (29) simultaneously, the transfer function $\left(V_{\mathrm{o}}\right.$ over $\left.d_{1}\right)$ of the buck converter can be obtained as

$$
\frac{\widehat{v}_{\mathrm{o}}(s)}{\widehat{d}_{1}(s)}=\frac{2 V_{\mathrm{i}}}{s^{2} L C+s\left((L / R)+\left((2 L C M) /\left(D_{1} T_{\mathrm{s}}(1-M)\right)\right)\right)+\left(\left((2-M) D_{1}\right) /((1-M) M)\right)} .
$$


4.3. Boost Converter Small Signal Transfer Function. For the boost converter, $V_{\mathrm{on}}=V_{\mathrm{i}}, V_{\mathrm{off}}=V_{\mathrm{i}}-V_{\mathrm{o}}$, and $i_{\mathrm{o}}=i_{\mathrm{D}}$, and Table 2 gives $I_{\mathrm{L}}=\left(D_{1}^{2} T_{\mathrm{s}} V_{\mathrm{i}} M\right) /(2 L(M-1))$ and $\left(D_{1}^{2} T_{s} R\right) /$ $(2 L)=M^{2}-M$; by substituting them into (21) and (25), it leads to

$$
\begin{aligned}
L \frac{d \hat{i}_{\mathrm{L}}}{d t}= & \left(\frac{V_{\mathrm{i}}+V_{\mathrm{o}}}{V_{\mathrm{i}}} D_{1}\right) \widehat{v}_{\mathrm{i}}-\left(\frac{V_{\mathrm{i}}}{V_{\mathrm{i}}-V_{\mathrm{o}}} D_{1}\right)\left(\widehat{v}_{\mathrm{i}}-\widehat{v}_{\mathrm{o}}\right) \\
& +2 V_{\mathrm{o}} \widehat{d}_{1}-\frac{V_{\mathrm{o}}}{I_{\mathrm{L}}} D_{1} \widehat{i}_{\mathrm{L}}, \\
C \frac{d \widehat{u}_{\mathrm{C}}}{d t}= & \widehat{i}_{\mathrm{L}}-\frac{D_{1} T_{\mathrm{s}} V_{\mathrm{i}}}{L} \widehat{d}_{1}-\frac{D_{1}^{2} T_{\mathrm{s}}}{2 L} \widehat{v}_{\mathrm{i}}-\frac{\widehat{u}_{\mathrm{C}}}{R} .
\end{aligned}
$$

Let $\widehat{v}_{i}=0$, then (31) will be

$$
\left(s L+\frac{2 L(M-1)}{D_{1} T_{s}}\right) \widehat{i}_{\mathrm{L}}=\frac{1}{1-M} D_{1} \widehat{v}_{\mathrm{o}}+2 V_{\mathrm{o}} \widehat{d}_{1},
$$

and if $u_{\mathrm{c}}=v_{\mathrm{o}}$ and $\widehat{v}_{\mathrm{i}}=0$, then we can obtain the following equation from (32):

$$
\left(s C+\frac{1}{R}\right) \widehat{v}_{\mathrm{o}}+\frac{D_{1} T_{\mathrm{s}} V_{\mathrm{i}}}{L} \widehat{d}_{1}=\widehat{i}_{\mathrm{L}} .
$$

Also considering (33) and (34) simultaneously, in this case, the transfer function of the boost converter will become

$$
\frac{\widehat{v}_{\mathrm{o}}(s)}{\widehat{d}_{1}(s)}=\frac{D_{1} T_{\mathrm{s}} V_{\mathrm{i}}\left(\left((2) /\left(D_{1} T_{\mathrm{s}}\right)\right)-s\right)}{s^{2} L C+s\left((L / R)+\left((2 L C(M-1)) /\left(D_{1} T_{\mathrm{s}}\right)\right)\right)+\left(\left((2 M-1) D_{1}\right) /(M(M-1))\right)}
$$

4.4. Buck-Boost Converter Small Signal Transfer Function. For the boost converter, $V_{\text {on }}=V_{\mathrm{i}}, V_{\mathrm{off}}=-V_{\mathrm{o}}$, and $i_{\mathrm{o}}=i_{\mathrm{D}}$, and from Table 2, $I_{\mathrm{L}}=\left(D_{1}^{2} T_{\mathrm{s}} V_{\mathrm{i}}(1+M)\right) /(2 L M)$ and $\left(D_{1}^{2} T_{s} R\right) /(2 L)=M^{2}$. Then, by substituting them into (21) and (25), we have

$$
\begin{aligned}
& L \frac{d \hat{i}_{\mathrm{L}}}{d t}=\left(\frac{2 V_{\mathrm{i}}+V_{\mathrm{o}}}{V_{\mathrm{i}}} D_{1}\right) \widehat{v}_{\mathrm{i}}-\frac{V_{\mathrm{i}}}{V_{\mathrm{o}}} D_{1} \widehat{v}_{\mathrm{o}} \\
&+2\left(V_{\mathrm{i}}+V_{\mathrm{o}}\right) \widehat{d}_{1}-\frac{\left(V_{\mathrm{i}}+V_{\mathrm{o}}\right)_{1}}{I_{\mathrm{L}}} D_{1} \widehat{i}_{\mathrm{L}} \\
& C \frac{d \widehat{u}_{\mathrm{C}}}{d t}=\widehat{i}_{\mathrm{L}}-\frac{D_{1} T_{\mathrm{s}} V_{\mathrm{i}}}{L} \widehat{d}_{1}-\frac{D_{1}^{2} T_{\mathrm{s}}}{2 L} \widehat{v}_{\mathrm{i}}-\frac{\widehat{u}_{\mathrm{C}}}{R} .
\end{aligned}
$$

With $\widehat{v}_{i}=0$, then (36) will lead to

$$
\left(s L+\frac{2 L M}{D_{1} T_{\mathrm{s}}}\right) \widehat{i}_{\mathrm{L}}=-\frac{1}{M} D_{1} \widehat{v}_{\mathrm{o}}+2\left(V_{\mathrm{i}}+V_{\mathrm{o}}\right) \widehat{d}_{1},
$$

and again if $u_{\mathrm{c}}=v_{\mathrm{o}}$ and $\widehat{v}_{i}=0$, (37) yields

$$
\left(s C+\frac{1}{R}\right) \widehat{v}_{\mathrm{o}}+\frac{D_{1} T_{s} V_{\mathrm{i}}}{L} \widehat{d}_{1}=\widehat{i}_{\mathrm{L}} \text {. }
$$

Finally, considering (38) and (39) simultaneously, again the transfer function of the buck-boost converter will be

$\frac{\widehat{v}_{\mathrm{o}}(s)}{\widehat{d}_{1}(s)}=\frac{D_{1} T_{\mathrm{s}} V_{\mathrm{i}}\left(\left(2 /\left(D_{1} T_{\mathrm{s}}\right)\right)-s\right)}{s^{2} L C+s\left((L / R)+\left((2 L C M) /\left(D_{1} T_{\mathrm{s}}\right)\right)\right)+\left(\left(2 D_{1}\right) / M\right)}$.
4.5. KY Converter Small Signal Transfer Function. For the KY converter, $V_{\text {on }}=2 V_{\mathrm{i}}-V_{\mathrm{o}}, V_{\text {off }}=V_{\mathrm{i}}-V_{\mathrm{o}}$, and $i_{\mathrm{o}}=i_{\mathrm{L}}$, and from Table 2, $I_{\mathrm{L}}=\left(D_{1}^{2} T_{\mathrm{s}} V_{\mathrm{i}}(2-M)\right) /(2 L(M-1))$ and $\left(D_{1}^{2} T_{s} R\right) /(2 L)=(M(M-1)) /(2-M)$. Then, substituting them into (21) and (23) will lead to

$$
\begin{aligned}
L \frac{d \hat{i}_{\mathrm{L}}}{d t}= & \frac{3 V_{\mathrm{i}}-V_{\mathrm{o}}}{2 V_{\mathrm{i}}-V_{\mathrm{o}}} D_{1}\left(2 \widehat{v}_{\mathrm{i}}-\widehat{v}_{\mathrm{o}}\right) \\
& -\frac{2 V_{\mathrm{i}}-V_{\mathrm{o}}}{V_{\mathrm{i}}-V_{\mathrm{o}}} D_{1}\left(\widehat{v}_{\mathrm{i}}-\widehat{v}_{\mathrm{o}}\right)+2 V_{\mathrm{i}} \widehat{d}_{1}-\frac{V_{\mathrm{i}}}{I_{\mathrm{L}}} D_{1} \widehat{i}_{\mathrm{L}}, \\
C \frac{d \widehat{u}_{\mathrm{C}}}{d t}= & \widehat{i}_{\mathrm{L}}-\frac{\widehat{u}_{\mathrm{C}}}{R} .
\end{aligned}
$$

Let $\widehat{v}_{i}=0$, then (41) becomes

$$
\left(s L+\frac{2 L(M-1)}{D_{1} T_{\mathrm{s}}(2-M)}\right) \widehat{i}_{\mathrm{L}}=\frac{1}{((2-M)(1-M))} D_{1} \widehat{v}_{\mathrm{o}}+2 V_{\mathrm{i}} \widehat{d}_{1} .
$$

Then with $\mathrm{uc}=$ vo, $(42)$ gives

$$
\left(s C+\frac{1}{R}\right) \widehat{v}_{\mathrm{o}}=\widehat{i}_{\mathrm{L}} .
$$

Again with (43) and (44) considered simultaneously, the transfer function of the KY converter can be obtained as

$$
\frac{\widehat{v}_{\mathrm{o}}(s)}{\widehat{d}_{1}(s)}=\frac{2 V_{\mathrm{i}}}{s^{2} L C+s\left((L / R)+\left((2 L C(M-1)) /\left(D_{1} T_{s}(2-M)\right)\right)\right)+\left(\left(\left(M^{2}-4 M+2\right) D_{1}\right) /((2-M)(1-M) M)\right)} .
$$




\section{Circuit Averaging Method for Large-Signal and Small Signal Modeling Deduction}

In this section, the approach for deducing the DCM small signal models for different DC-DC converters by using the CA method will be discussed.

5.1. General Large-Signal and Corresponding Small Signal Modeling Using the CA Method. With the help of Reference [10], according to (7) and (8), the switching network of the DC-DC converter can be transformed into the circuit as shown in Figure 4.

When the circuit reaches the steady-state, the average voltage across the inductor is zero, then Figure 4 imposes,

$$
V_{\text {LM }}=0 \text {. }
$$

From Figure 4, we can obtain

$$
\begin{gathered}
V_{\mathrm{LS}}=V_{\mathrm{LM}}+V_{\mathrm{MS}}=V_{\mathrm{MS}}, \\
V_{\mathrm{LD}}=V_{\mathrm{LM}}+V_{\mathrm{MD}}=V_{\mathrm{MD}} .
\end{gathered}
$$

By using (5)-(8), they yield the following large-signal equations (considering identical the large-signal value and the DC value relationships):

$$
\begin{aligned}
& i_{\mathrm{S}}=\frac{d_{1}^{2} T_{\mathrm{s}} v_{\mathrm{on}}}{2 L}, \\
& i_{\mathrm{D}}=-\frac{d_{1}^{2} T_{\mathrm{s}} v_{\mathrm{on}}^{2}}{2 L v_{\mathrm{off}}} .
\end{aligned}
$$

Taking the derivative of (49) and (50), the corresponding small signal equations will emerge as follows:

$$
\begin{aligned}
& \widehat{i}_{\mathrm{S}}=\frac{D_{1} T_{\mathrm{s}} V_{\text {on }}}{L} \widehat{d}_{1}+\frac{D_{1}^{2} T_{\mathrm{s}}}{2 L} \widehat{v}_{\text {on }}, \\
& \widehat{i}_{\mathrm{D}}=-\frac{D_{1} T_{\mathrm{s}} V_{\text {on }}^{2}}{L V_{\text {off }}} \widehat{d}_{1}-\frac{D_{1}^{2} T_{\mathrm{s}} V_{\text {on }}}{L V_{\text {off }}} \widehat{v}_{\text {on }}+\frac{D_{1}^{2} T_{\mathrm{s}} V_{\text {on }}^{2}}{2 L V_{\text {off }}^{2}} \widehat{v}_{\text {off }},
\end{aligned}
$$

and from (47) and (48), $V_{\text {on }}=V_{\mathrm{LS}}=V_{\mathrm{MS}}$ and $V_{\mathrm{off}}=V_{\mathrm{LD}}=$ $V_{\mathrm{MD}}$. Then, the small signal circuit of the switching network in Figure 4 can be transformed into Figure 5, where

$$
\begin{aligned}
& k_{S}=\frac{D_{1} T_{s} V_{\text {on }}}{L}, \\
& g_{\mathrm{S}}=\frac{D_{1}^{2} T_{\mathrm{s}}}{2 L}, \\
& k_{\mathrm{D}}=-\frac{D_{1} T_{\mathrm{s}} V_{\mathrm{on}}^{2}}{L V_{\mathrm{off}}}, \\
& g_{\mathrm{D}}=-\frac{D_{1}^{2} T_{\mathrm{s}} V_{\mathrm{on}}}{L V_{\mathrm{off}}}, \\
& g_{\mathrm{M}}=\frac{D_{1}^{2} T_{\mathrm{s}} V_{\mathrm{on}}^{2}}{2 L V_{\mathrm{off}}^{2}} .
\end{aligned}
$$

From Figure 5, we can write

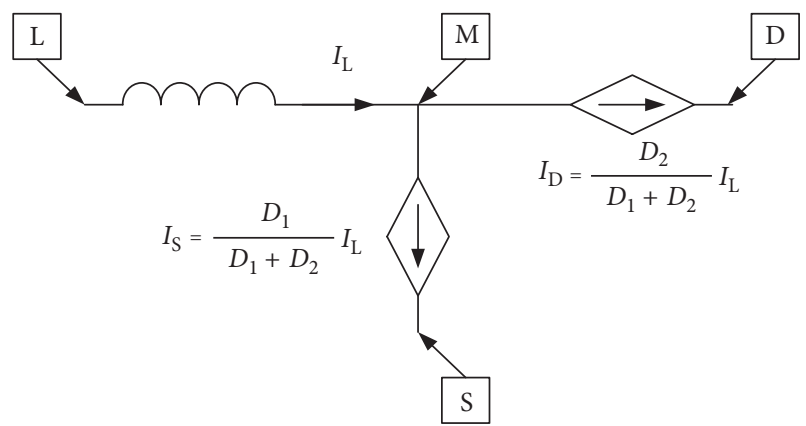

FIgURE 4: Equivalent circuit of the switching network (current source).

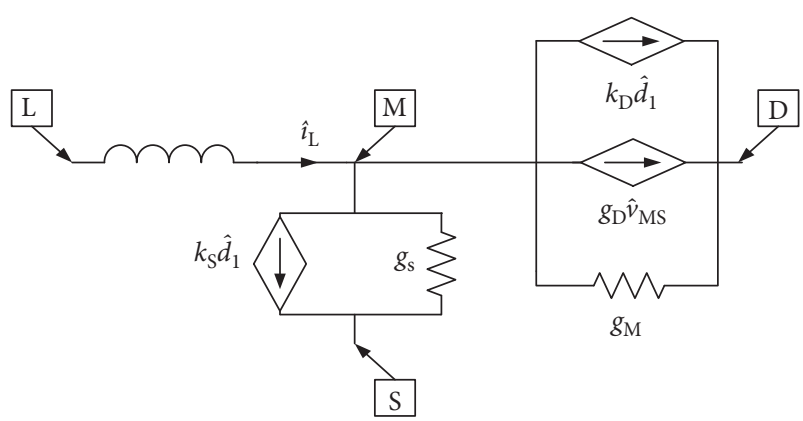

FIGURE 5: Small signal equivalent circuit of the switching network.

$$
\begin{aligned}
\widehat{i}_{\mathrm{L}} & =\left(k_{\mathrm{S}}+k_{\mathrm{D}}\right) \widehat{d}_{1}+\left(g_{\mathrm{S}}+g_{\mathrm{D}}\right) \widehat{v}_{\mathrm{MS}}+g_{\mathrm{M}} \widehat{v}_{\mathrm{MD}}, \\
& =\left(k_{\mathrm{S}}+k_{\mathrm{D}}\right) \widehat{d}_{1}+\left(g_{\mathrm{S}}+g_{\mathrm{D}}+g_{\mathrm{M}}\right) \widehat{v}_{\mathrm{MS}}+g_{\mathrm{M}} \widehat{v}_{\mathrm{SD}} .
\end{aligned}
$$

Then, with $k_{\mathrm{d} 1}=k_{\mathrm{S}}+k_{\mathrm{D}}$ and $g_{\mathrm{MS}}=g_{\mathrm{S}}+g_{\mathrm{D}}+g_{\mathrm{M}}$, we can obtain the factors $k_{\mathrm{S}}, k_{\mathrm{D}}, k_{\mathrm{d} 1}, g_{\mathrm{S}}, g_{\mathrm{D}}, g_{\mathrm{M}}$, and $g_{\mathrm{MS}}$ of the four DC-DC converters (buck, boost, buck-boost, and KY) as shown in Table 3.

With these factors, we can substantially simplify the calculation process, as shown next. Further, we can deduce that

$$
\begin{aligned}
& \widehat{v}_{\mathrm{LM}}=s L \widehat{i}_{\mathrm{L}}, \\
& \widehat{v}_{\mathrm{MS}}=\widehat{v}_{\mathrm{LS}}-\widehat{v}_{\mathrm{LM}} .
\end{aligned}
$$

Then (53) can be rewritten as

$$
\left(s L+\frac{1}{g_{\mathrm{MS}}}\right) \widehat{i}_{\mathrm{L}}=\frac{k_{d_{1}}}{g_{\mathrm{MS}}} \widehat{d}_{1}+\widehat{v}_{\mathrm{LS}}+\frac{g_{\mathrm{M}}}{g_{\mathrm{MS}}} \widehat{v}_{\mathrm{SD}},
$$

and considering the capacitor, its current becomes

$$
C \frac{d \widehat{u}_{\mathrm{C}}}{d t}=\widehat{i}_{\mathrm{o}}-\frac{\widehat{u}_{\mathrm{C}}}{R}
$$

If $i_{\mathrm{o}}=i_{\mathrm{L}}$, (57) will become

$$
C \frac{d \widehat{u}_{\mathrm{C}}}{d t}=\widehat{i}_{\mathrm{L}}-\frac{\widehat{u}_{\mathrm{C}}}{R}
$$

Then, with $u_{\mathrm{c}}=v_{\mathrm{o}}$, we have 
TABLE 3: Relevant factors of the circuit averaging (CA) method.

\begin{tabular}{lcccc}
\hline DC-DC converter & Buck & Boost & Buck-boost & KY \\
\hline$k_{\mathrm{S}}$ & $\left(2 M^{2} V_{\mathrm{i}}\right) /\left(D_{1} R\right)$ & $\left(2 M(M-1) V_{\mathrm{i}}\right) /\left(D_{1} R\right)$ & $\left(2 M^{2} V_{\mathrm{i}}\right) /\left(D_{1} R\right)$ & $\left(2 M(M-1) V_{\mathrm{i}}\right) /\left(D_{1} R\right)$ \\
$k_{\mathrm{D}}$ & $\left(\left(2 M(1-M) V_{\mathrm{i}}\right) /\left(D_{1} R\right)\right)$ & $\left(2 M V_{\mathrm{i}}\right) /\left(D_{1} R\right)$ & $\left(2 M V_{\mathrm{i}}\right) /\left(D_{1} R\right)$ & $\left(2 M(2-M) V_{\mathrm{i}}\right) /\left(D_{1} R\right)$ \\
$k_{\mathrm{d} 1}$ & $\left(2 M V_{\mathrm{i}}\right) /\left(D_{1} R\right)$ & $\left(2 M^{2} V_{\mathrm{i}}\right) /\left(D_{1} R\right)$ & $\left(2 M(M+1) V_{\mathrm{i}}\right) /\left(D_{1} R\right)$ & $\left(2 M V_{\mathrm{i}}\right) /\left(D_{1} R\right)$ \\
$g_{\mathrm{S}}$ & $\left(M^{2}\right) /((-M) R)$ & $\left(M^{2}-M\right) /(R)$ & $(M)^{2} / R$ & $(M(M-1)) /((2-M) R)$ \\
$g_{\mathrm{D}}$ & $(2 M) / R$ & $(2 M) / R$ & $(2 M) / R$ & $(2 M) / R$ \\
$g_{\mathrm{M}}$ & $(1-M) / R$ & $M /((M-1) R)$ & $1 / R$ & $(M(2-M)) /((M-1) R)$ \\
$g_{\mathrm{MS}}$ & $1 /((1-M) R)$ & $M^{3} /((M-1) R)$ & $\left((M+1)^{2}\right) / R$ & $M /((2-M)(M-1))$ \\
\hline
\end{tabular}

$$
\widehat{i}_{\mathrm{L}}=\left(S C+\frac{1}{R}\right) \widehat{v}_{\mathrm{o}}
$$

and with $i_{\mathrm{o}}=i_{\mathrm{D}}$, (57) yields

$$
C \frac{d \widehat{u}_{\mathrm{C}}}{d t}=k_{\mathrm{D}} \widehat{d}_{1}+g_{\mathrm{D}} \widehat{v}_{\mathrm{MS}}+g_{\mathrm{M}} \widehat{v}_{\mathrm{MD}}-\frac{\widehat{u}_{\mathrm{C}}}{R} .
$$

Finally, with (54)-(56), $u_{\mathrm{c}}=v_{\mathrm{o}}$, (60) can be rewritten as

$$
\begin{aligned}
\hat{i}_{\mathrm{L}}= & \frac{g_{\mathrm{MS}}}{g_{\mathrm{D}}+g_{\mathrm{M}}}\left(S C+\frac{1}{R}\right) \widehat{v}_{\mathrm{o}} \\
& +\left(k_{d 1}-\frac{k_{\mathrm{D}} \cdot g_{\mathrm{MS}}}{g_{\mathrm{D}}+g_{\mathrm{M}}}\right) \widehat{d}_{1}+\left(g_{\mathrm{M}}-\frac{g_{\mathrm{M}} \cdot g_{\mathrm{MS}}}{g_{\mathrm{D}}+g_{\mathrm{M}}}\right) \widehat{v}_{\mathrm{SD}} .
\end{aligned}
$$

Here, (56), (59), and (61) are the 3 general equations to deduce the DCM small signal models for the different DCDC converters. By just input, the voltage drops $V_{\mathrm{LS}}$ and $V_{\mathrm{SD}}$ from Figure 5, plus the factors (Table 3 ) and the DC parameters (Table 2) into (56), (59) and (61), and the corresponding DCM small signal transfer functions can be calculated easily in the following.

5.2. Buck Converter Small Signal Transfer Function. For the buck converter, from Figure $5, V_{\mathrm{LS}}=V_{\mathrm{i}}-V_{\mathrm{o}}, V_{\mathrm{SD}}=-V_{\mathrm{i}}$, and $i_{\mathrm{o}}=i_{\mathrm{L}}$, and from Table $2, I_{\mathrm{L}}=\left(D_{1}^{2} T_{\mathrm{s}} V_{\mathrm{i}}(1-M)\right) /(2 L M)$ and $\left(D^{2} T_{\mathrm{s}} R\right) /(2 L)=M^{2} /(1-M)$. Then, with $\widehat{v}_{\mathrm{i}}=0$, (56) and (59) lead to

$$
(s L+(1-M) R) \widehat{i}_{\mathrm{L}}=\frac{2 M(1-M) V_{\mathrm{i}}}{D_{1}} \widehat{d}_{1}-\widehat{v}_{\mathrm{o}}
$$

$$
\widehat{i}_{\mathrm{L}}=\left(s C+\frac{1}{R}\right) \widehat{v}_{\mathrm{o}} .
$$

And from (62) and (63) simultaneously, the transfer function of the buck converter can be obtained as

$$
\frac{\widehat{v}_{\mathrm{o}}(s)}{\widehat{d}_{1}(s)}=\frac{M(1-M)\left(\left(2 V_{\mathrm{i}}\right) / D_{1}\right)}{s^{2} L C+s((L / R)+R C(1-M))+2-M} \text {. }
$$

5.3. Boost Converter Small Signal Transfer Function. For the boost converter, from Figure $5, V_{\mathrm{LS}}=V_{\mathrm{i}}, V_{\mathrm{SD}}=-V_{\mathrm{o}}, i_{\mathrm{o}}=i_{\mathrm{D}}$, and from Table 2, $I_{\mathrm{L}}=\left(D_{1}^{2} T_{\mathrm{s}} V_{\mathrm{i}} M\right) /(2 L(M-1))$ and $\left(D_{1}^{2} T_{s} R\right) /(2 L)=M^{2}-M$. Then, with $\widehat{v}_{\mathrm{i}}=0$, (56) and (61) imply,

$$
\begin{aligned}
\left(s L+\frac{(M-1) R}{M^{3}}\right) \widehat{i}_{\mathrm{L}}= & \frac{2(M-1) V_{\mathrm{i}}}{D_{1} M} \widehat{d}_{1}-\frac{1}{M^{2}} \widehat{v}_{\mathrm{o}}, \\
\hat{i}_{\mathrm{L}}= & \frac{M^{2}}{2 M-1}\left(s C+\frac{2 M-1}{M R}\right) \widehat{v}_{\mathrm{o}} \\
& +\frac{2(M-1) M^{2} V_{\mathrm{i}}}{(2 M-1) D_{1} R} .
\end{aligned}
$$

Again, from (65) and (66) simultaneously, the transfer function of the boost converter will become,

$$
\frac{\widehat{v}_{\mathrm{o}}(s)}{\widehat{d}_{1}(s)}=\frac{\left(\left(D_{1} T_{\mathrm{s}} V_{\mathrm{i}}\right) / M\right)\left(\left((2(M-1)) /\left(D_{1}^{2} T_{\mathrm{s}} M\right)\right)-s\right)}{s^{2} L C+s\left(((L(2 M-1)) /(R M))+\left((R C(M-1)) /\left(M^{3}\right)\right)\right)+\left((2 M-1) / M^{3}\right)} .
$$

5.4. Buck-Boost Converter Small Signal Transfer Function. For the buck-boost converter, from Figure 5, $V_{\mathrm{LS}}=V_{\mathrm{i}}, V_{\mathrm{SD}}=$ $-\left(V_{\mathrm{i}}+V_{\mathrm{o}}\right)$, and $i_{\mathrm{o}}=i_{\mathrm{D}}$, and from Table $2, I_{\mathrm{L}}=\left(D_{1}^{2} T_{\mathrm{s}} V_{\mathrm{i}}(1+\right.$ $M)) /(2 L M)$ and $\left(D_{1}^{2} T_{s} R\right) /(2 L)=M^{2}$. Then, with $\widehat{v}_{i}=0$, (56) and (61) impose

$$
\left(s L+\frac{R}{(M+1)^{2}}\right) \widehat{i}_{\mathrm{L}}=\frac{2 M V_{\mathrm{i}}}{D_{1}(M+1)} \widehat{d}_{1}-\frac{1}{(M+1)^{2}} \widehat{v}_{\mathrm{o}},
$$

$$
\begin{aligned}
\widehat{i}_{\mathrm{L}}= & \frac{(M+1)^{2}}{2 M+1}\left(S C+\frac{2 M^{2}+2 M+1}{(M+1)^{2} R}\right) \widehat{v}_{\mathrm{O}} \\
& +\frac{2\left(M^{3}+M^{2}\right) V_{\mathrm{i}}}{(2 M+1) D_{1} R} \widehat{d}_{1} .
\end{aligned}
$$

Similarly, with (68) and (69) considered simultaneously, the transfer function of the buck-boost converter will be 


$$
\frac{\widehat{v}_{\mathrm{o}}(s)}{\widehat{d}_{1}(s)}=\frac{\left(\left(D_{1} T_{\mathrm{s}} V_{\mathrm{i}}\right) /(M+1)\right)\left(\left((2 M) /\left(D_{1}^{2} T_{\mathrm{s}}(M+1)\right)\right)-s\right)}{s^{2} L C+s\left(\left(\left(L\left(2 M^{2}+2 M+1\right)\right) /\left(R(M+1)^{2}\right)\right)+\left((R C) /\left((M+1)^{2}\right)\right)\right)+\left(2 /\left((M+1)^{2}\right)\right)} .
$$

6.5. KY Converter Small Signal Transfer Function. For the KY converter, from Figure $5, V_{\mathrm{LS}}=2 V_{\mathrm{i}}-V_{\mathrm{o}}, V_{\mathrm{SD}}=-V_{\mathrm{i}}$, and $i_{\mathrm{o}}=$ $i_{\mathrm{L}}$, and from Table $2, I_{\mathrm{L}}=\left(D_{1}^{2} T_{\mathrm{s}} V_{\mathrm{i}}(2-M)\right) /(2 L(M-1))$ and $\left(D_{1}^{2} T_{\mathrm{s}} R\right) /(2 L)=(M(M-1)) /((2-M))$. Then, with $\widehat{v}_{\mathrm{i}}=0$, (56) and (59) entail

$$
\left(s L+\frac{(2-M)(M-1) R}{M}\right) \hat{i}_{\mathrm{L}}=\frac{2(2-M)(M-1) V_{\mathrm{i}}}{D_{1}} \widehat{d}_{1}-\widehat{v}_{\mathrm{o}},
$$

$$
\widehat{i}_{\mathrm{L}}=\left(s C+\frac{1}{R}\right) \widehat{v}_{\mathrm{o}} .
$$

Finally, from (71) and (72) simultaneously, the transfer function of the KY converter will become

$$
\frac{\widehat{v}_{\mathrm{o}}(s)}{\widehat{d}_{1}(s)}=\frac{(2-M)(M-1)\left(\left(2 V_{\mathrm{i}}\right) / D_{1}\right)}{s^{2} L C+s((L / R)+((R C(2-M)(M-1)) / M))+(((2-M)(M-1)+M) / M)} .
$$

\section{Simulation Results}

We simulated the four DC-DC converters within a Cadence environment of a $65 \mathrm{~nm}$ CMOS process and also MATLAB to verify and compare the accuracy of the small signal transfer functions (30), (35), (40), (45), (64), (67), (70), and (73) deduced by the improved SSA and CA methods.

6.1. Buck Converter. The relevant parameters of the buck converter (Figure 2) are $V_{\mathrm{i}}=1.2 \mathrm{~V}, f_{\mathrm{s}}=100 \mathrm{MHz}, C=10 \mathrm{nF}$, $L=36 \mathrm{nH}$, and $R=40 \Omega$. The Bode plot comparison between the transfer functions with the SSA and the CA methods ((30) and (64)), and the simulated circuit power stage (PS), is shown in Figure 6, for $d_{1}=0.3,0.5$, and 0.7.

From Figure 6, we can conclude that in the buck converter, the CA method provides higher accuracy than the SSA method in any duty ratio range $d_{1}$, with clearer emphasis at larger $d_{1}$ values.

6.2. Boost Converter. The relevant parameters of the boost converter (Figure 2) are $V_{\mathrm{i}}=1.2 \mathrm{~V}, f_{\mathrm{s}}=100 \mathrm{MHz}, C=10 \mathrm{nF}$, $L=13.5 \mathrm{nH}$, and $R=60 \Omega$. The Bode plot comparison between the transfer functions with the SSA and the CA methods ((35) and (67)), and the simulated circuit PS, is shown in Figure 7, for $d_{1}=0.3,0.5$, and 0.7.

From Figure 7 , we can conclude that in the boost converter with a small duty ratio value $\left(d_{1}=0.3\right)$, the SSA method contains slightly better accuracy than the CA method. But, as the $d_{1}$ increases, the accuracy of the CA method will improve over the SSA method, again being more evident for larger $d_{1}$ values.

6.3. Buck-Boost Converter. The relevant parameters of the buck-boost converter (Figure 2) are $V_{\mathrm{i}}=1.2 \mathrm{~V}, f_{\mathrm{s}}=100 \mathrm{MHz}$, $C=40 \mathrm{nF}, L=15 \mathrm{nH}$, and $R=150 \Omega$. The Bode plot comparison between the transfer functions with the SSA and the CA methods ((40) and (70)), and the simulated circuit PS, is shown in Figure 8, for $d_{1}=0.3,0.5$, and 0.7.

From Figure 8, the analysis of the simulation results of the boost converter is similar to those of the buck-boost converter, leading exactly to the same conclusions.

6.4. KY Converter. Finally, for the KY converter (Figure 2), $V_{\mathrm{i}}=1.2 \mathrm{~V}, f_{\mathrm{s}}=100 \mathrm{MHz}, C=10 \mathrm{nF}, C_{\mathrm{f}}=10 \mathrm{nF}, L=3.6 \mathrm{nH}$, and $R=60 \Omega$, and the Bode plot comparison between the transfer functions with the SSA and the CA methods ((45) and (73)), and the simulated circuit PS, is shown in Figure 9, for $d_{1}=0.3,0.5$, and 0.7 .

From Figure 9, the analysis of the simulation results of the KY converter are similar to those of the buck converter, leading exactly to the same conclusions.

\section{High-Accuracy Modeling Method for Different DC-DC Converters in DCM-Selection Strategy}

7.1. Derivation. By using the methods presented in [3] and [6], the approximate poles and zeros for different DC-DC converters in DCM with the SSA and CA methods can be calculated and summarized in Table 4. The previous Bode plot simulation results clearly demonstrate that the phasefrequency responses of the DC-DC converters power stages generally show a larger phase lag than the small signal models given by both the SSA and CA methods. Based on this, if the modeling method presents a smaller value of the second pole or zero (leading to a larger phase lag), it will exhibit a better accuracy of the system phase-frequency response. From Table 4, we propose a selection strategy of high-accuracy small signal modeling method for the DC-DC converters as in Table 5.

7.2. Verification. For verification of the proposed selection strategy, we simulated a buck converter and a boost 

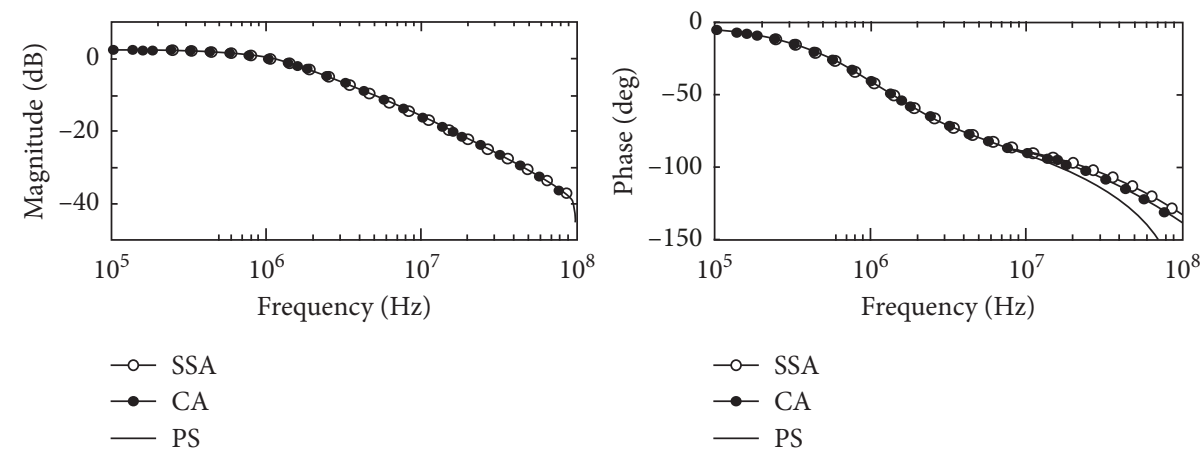

(a)
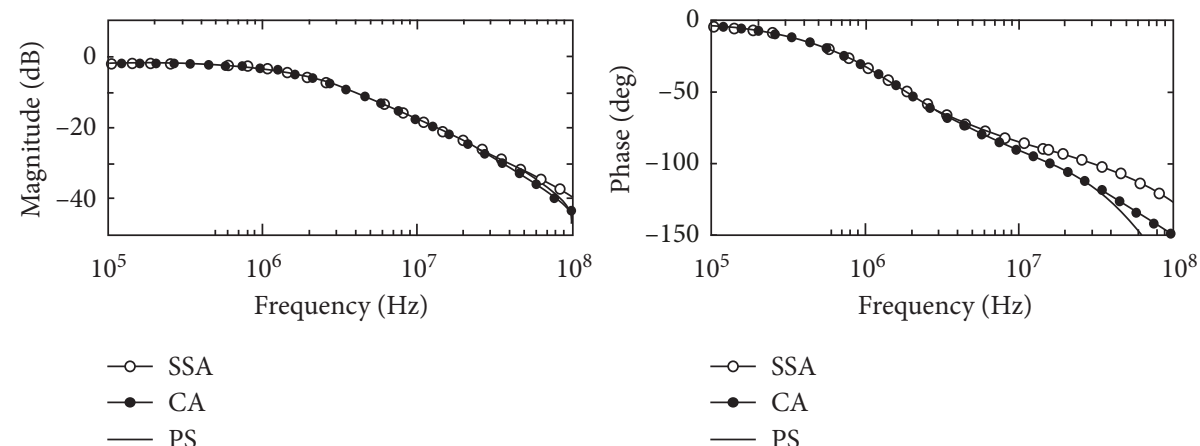

(b)
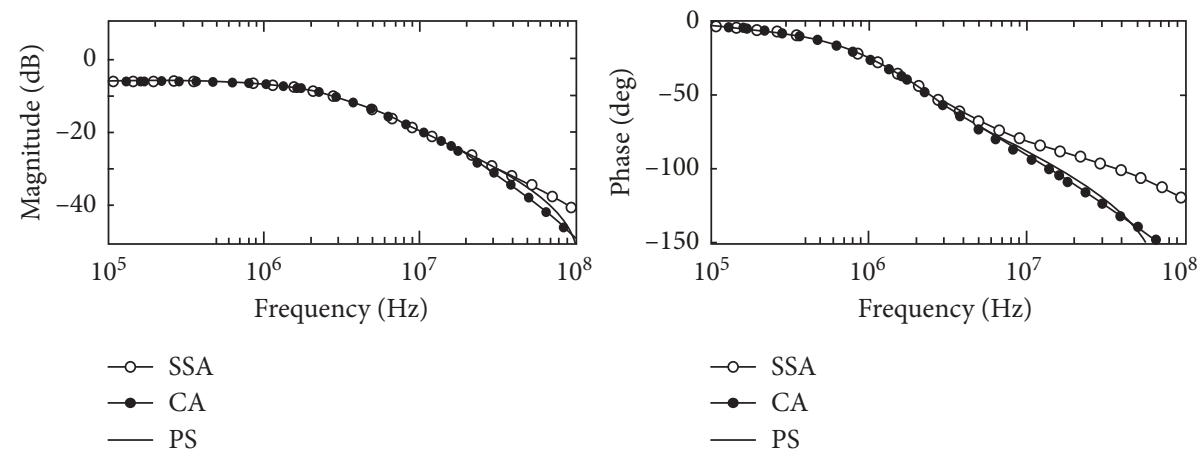

(c)

FIGURE 6: Small signal models comparison of the buck converter with SSA and CA methods: (a) $d_{1}=0.3$; (b) $d_{1}=0.5$; and (c) $d_{1}=0.7$.
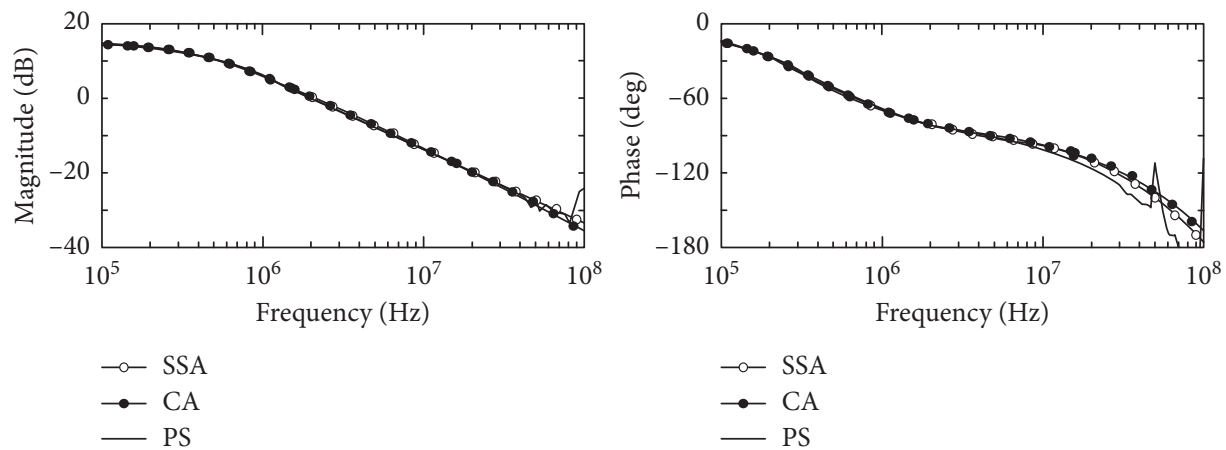

(a)

Figure 7: Continued. 

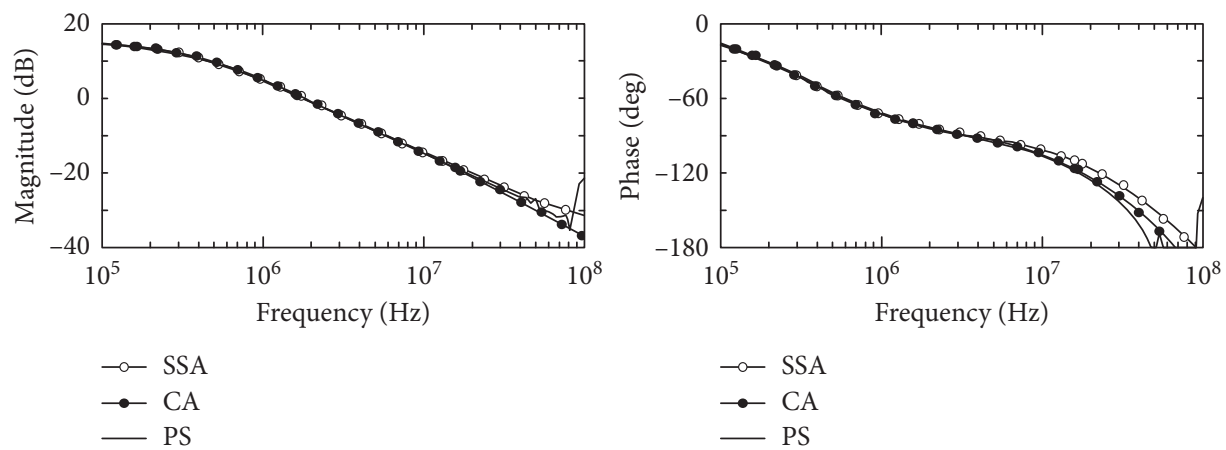

(b)
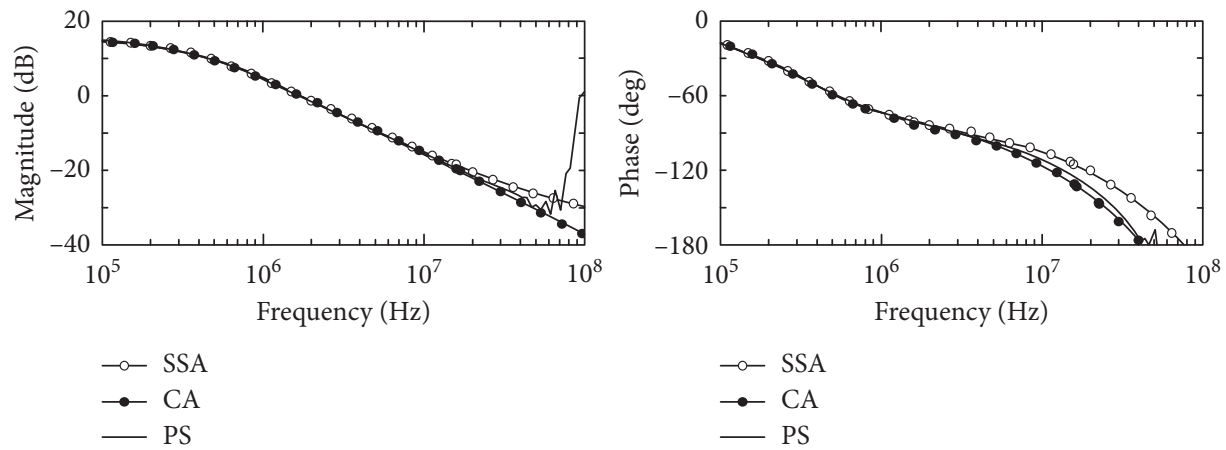

(c)

FIGURE 7: Small signal models comparison of the boost converter with SSA and CA methods: (a) $d_{1}=0.3$; (b) $d_{1}=0.5$; and (c) $d_{1}=0.7$.
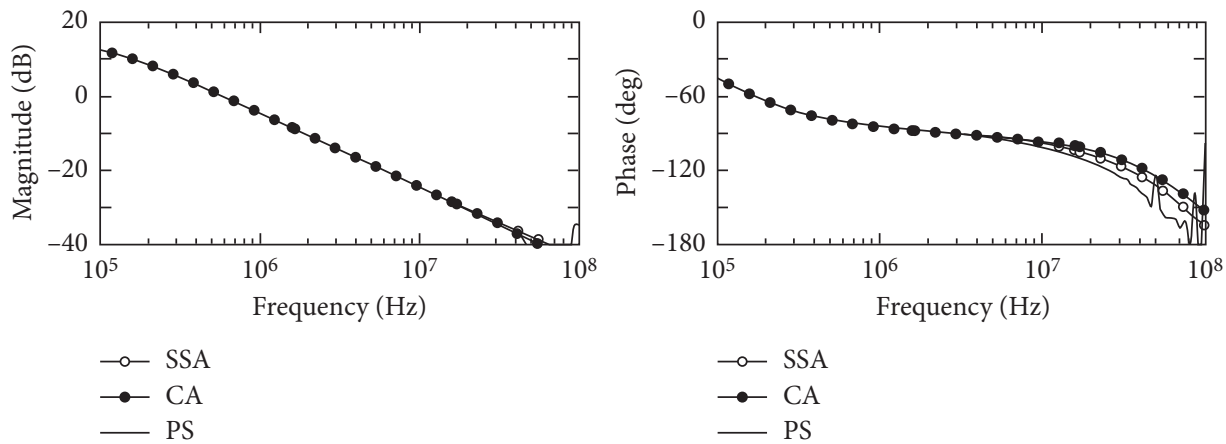

(a)
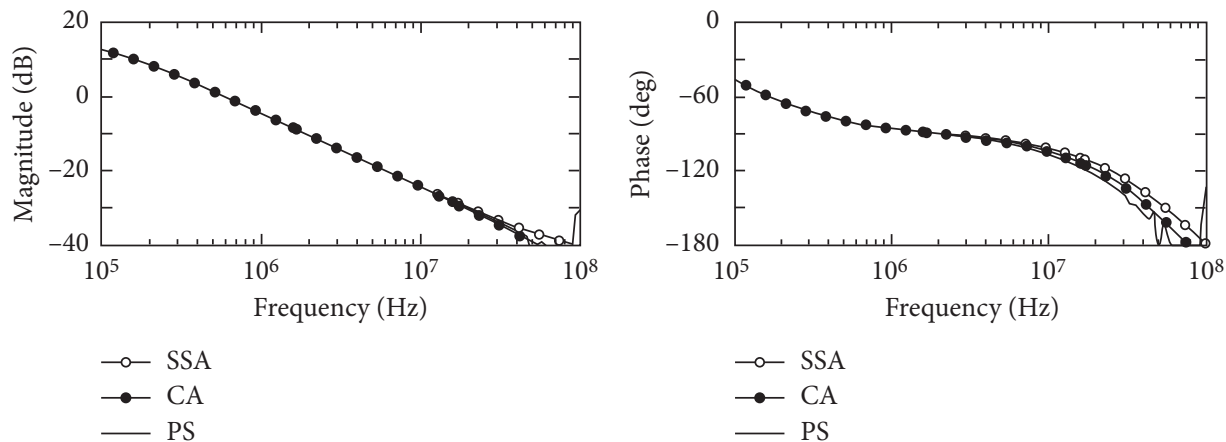

(b)

FIgURE 8: Continued. 

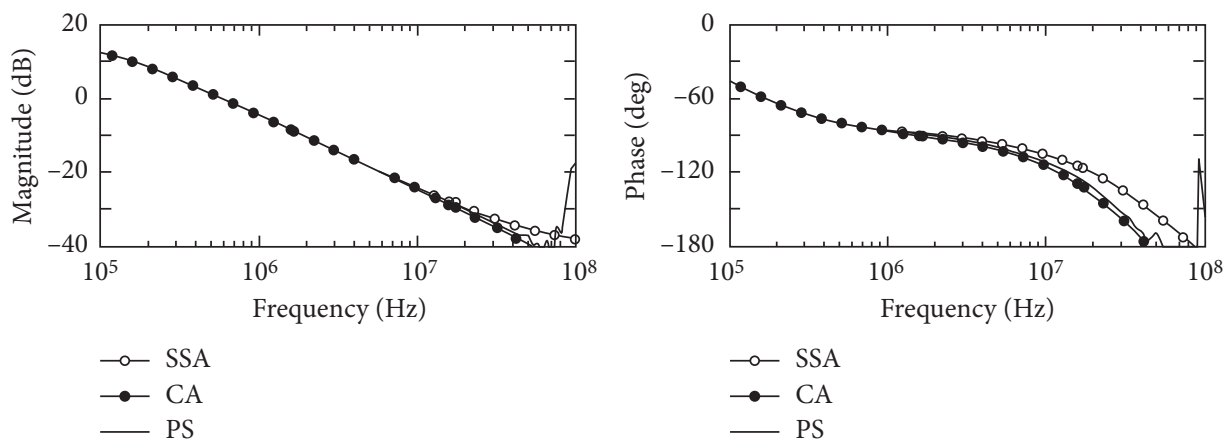

(c)

FIGURE 8: Small signal models comparison of the buck-boost converter with SSA and CA methods: (a) $d_{1}=0.3$; (b) $d_{1}=0.5$; and (c) $d_{1}=0.7$.
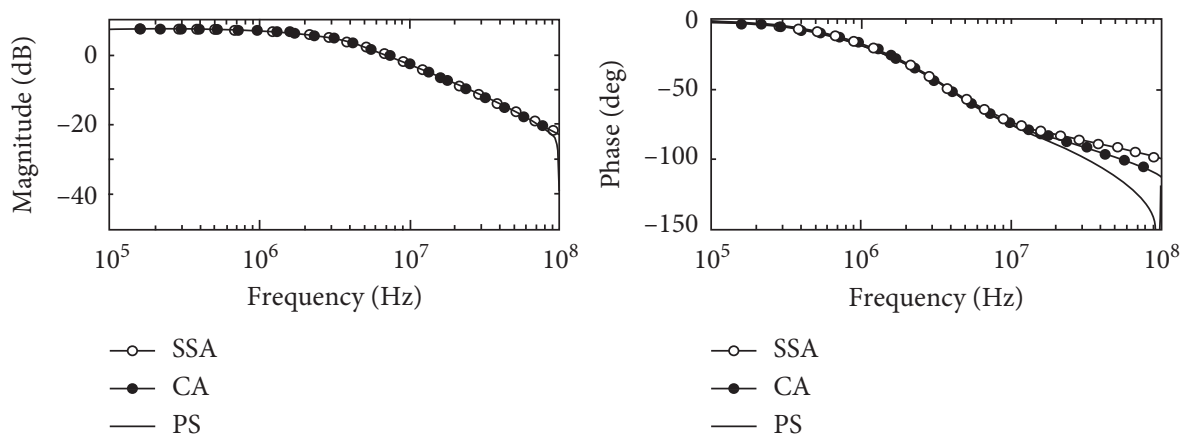

(a)
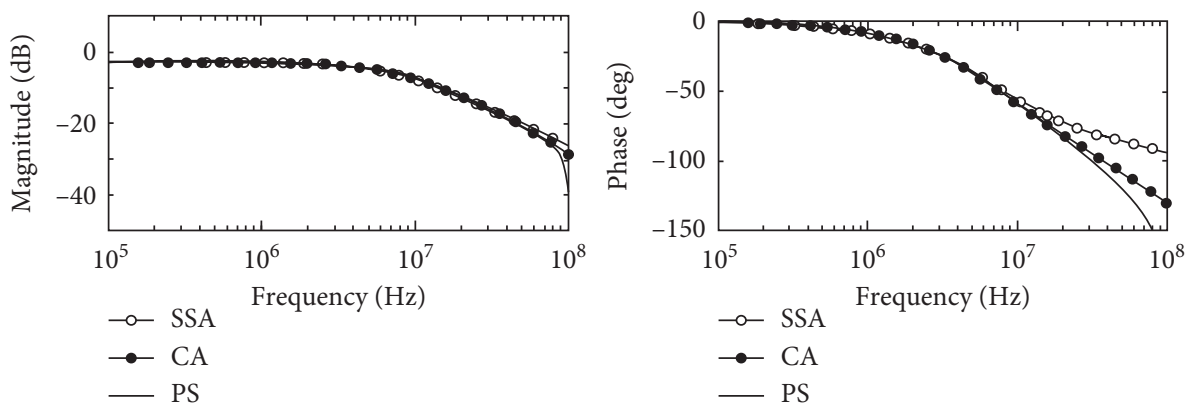

(b)
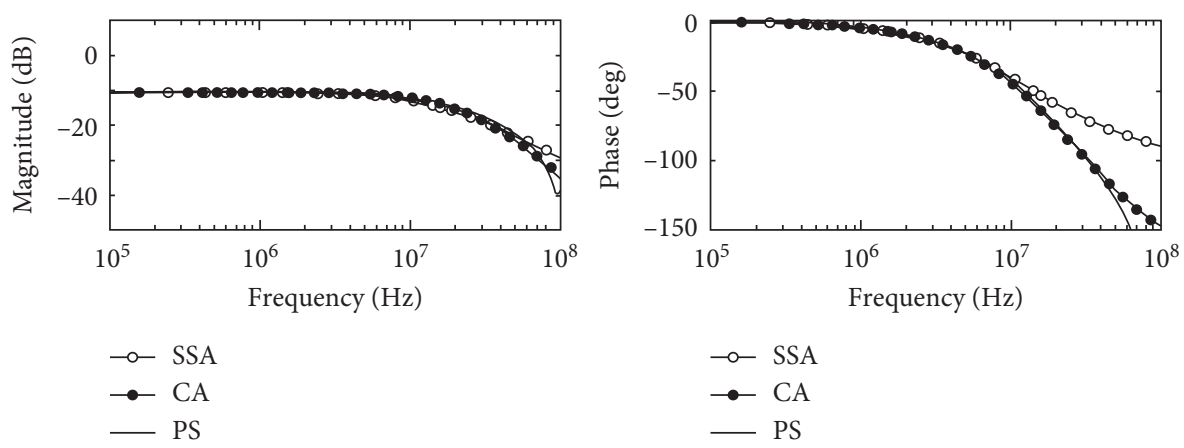

(c)

FIGURE 9: Small signal models comparison of the KY converter with SSA and CA methods: (a) $d_{1}=0.3$; (b) $d_{1}=0.5$; and $(\mathrm{c}) d_{1}=0.7$.

converter with the Cadence Spectre simulator to demonstrate that the converter operates with higher stability with a more accurate small signal modeling method used in the compensator design. The simulated results of the system phase-frequency response and the closed-loop controlled converters' load transient response are presented in 
TABLE 4: Approximate poles and zeros for various DC-DC converters in DCM.

\begin{tabular}{lcccc}
\hline Name & Method & First pole & Second pole & Zero \\
\hline \multirow{2}{*}{ Buck } & SSA & $(2-M) /(R C(1-M))$ & $(2 M) /\left(d_{1} T_{\mathrm{s}}(1-M)\right)$ & $\left(2 M^{2}\right) /\left(d_{1}^{2} T_{\mathrm{s}}\right)$ \\
\hline \multirow{2}{*}{ Boost } & CA & $(2-M) /(R C(1-M))$ & $(2(M-1)) /\left(d_{1} T_{\mathrm{s}}\right)$ & $2 /\left(d_{1} T_{\mathrm{s}}\right)$ \\
& SSA & $(2 M-1) /(R C(M-1))$ & $\left(2((M-1) / M)^{2}\right) /\left(d_{1}^{2} T_{\mathrm{s}}\right)$ & $(2((M-1) / M)) /\left(d_{1}^{2} T_{\mathrm{s}}\right)$ \\
\hline \multirow{2}{*}{ Buck-boost } & CA & $(2 M-1) /(R C(M-1))$ & $(2 M) /\left(d_{1} T_{\mathrm{s}}\right)$ & $2 /\left(d_{1} T_{\mathrm{s}}\right)$ \\
& SSA & $2 /(R C)$ & $2(M /(M+1))^{2} / d_{1}^{2} T_{\mathrm{s}}$ & $2(M /(M+1)) / d_{1}^{2} T_{\mathrm{s}}$ \\
\hline \multirow{2}{*}{ KY } & CA & $2 /(R C)$ & $(2(M-1)) /\left(d_{1} T_{\mathrm{s}}(2-M)\right)$ & \\
& SSA & $\left(M^{2}-4 M+2\right) /\left(R C\left(M^{2}-3 M+2\right)\right)$ & $\left(2(M-1)^{2}\right) /\left(d_{1}^{2} T_{\mathrm{s}}\right)$ & \\
\hline
\end{tabular}

TABLE 5: Selection strategy between SSA and CA for high-accuracy small signal modeling.

\begin{tabular}{|c|c|c|}
\hline Name & Criterion & Modeling selection \\
\hline Buck & $\begin{array}{l}\left(2 M /\left(d_{1} T_{s}(1-M)\right)\right)<\left(\left(2 M^{2}\right) /\left(d_{1}^{2} T_{s}\right)\right) \\
\left(2 M /\left(d_{1} T_{s}(1-M)\right)\right)>\left(\left(2 M^{2}\right) /\left(d_{1}^{2} T_{s}\right)\right)\end{array}$ & $\begin{array}{l}\text { SSA } \\
\text { CA } \\
\end{array}$ \\
\hline Boost & $\begin{array}{c}\min (((2(M-1)) / \\
\left.\left.\left(d_{1} T_{\mathrm{s}}\right)\right),\left(2 / d_{1} T_{\mathrm{s}}\right)\right)<\left(2((M-1) / M)^{2} /\left(d_{1}^{2} T_{\mathrm{s}}\right)\right) \\
\min \left(\left((2(M-1)) /\left(d_{1} T_{\mathrm{s}}\right)\right),\left(2 / d_{1} T_{\mathrm{s}}\right)\right)> \\
\left(2((M-1) / M)^{2} /\left(d_{1}^{2} T_{\mathrm{s}}\right)\right)\end{array}$ & SSA \\
\hline Buck-boost & $\begin{array}{c}\min (((2 M) / \\
\left.\left.\left(d_{1} T_{s}\right)\right),\left(2 / d_{1} T_{s}\right)\right)<\left(2(M /(M+1))^{2} /\left(d_{1}^{2} T_{s}\right)\right) \\
\min (((2 M) / \\
\left.\left.\left(d_{1} T_{s}\right)\right),\left(2 / d_{1} T_{s}\right)\right)>\left(2(M /(M+1))^{2} /\left(d_{1}^{2} T_{s}\right)\right)\end{array}$ & SSA \\
\hline KY & $\begin{array}{l}(2(M-1)) /\left(d_{1} T_{s}(2-M)\right)<\left(\left(2(M-1)^{2}\right) /\left(d_{1}^{2} T_{s}\right)\right) \\
(2(M-1)) /\left(d_{1} T_{s}(2-M)\right)>\left(\left(2(M-1)^{2}\right) /\left(d_{1}^{2} T_{s}\right)\right)\end{array}$ & $\begin{array}{l}\text { SSA } \\
\text { CA }\end{array}$ \\
\hline
\end{tabular}
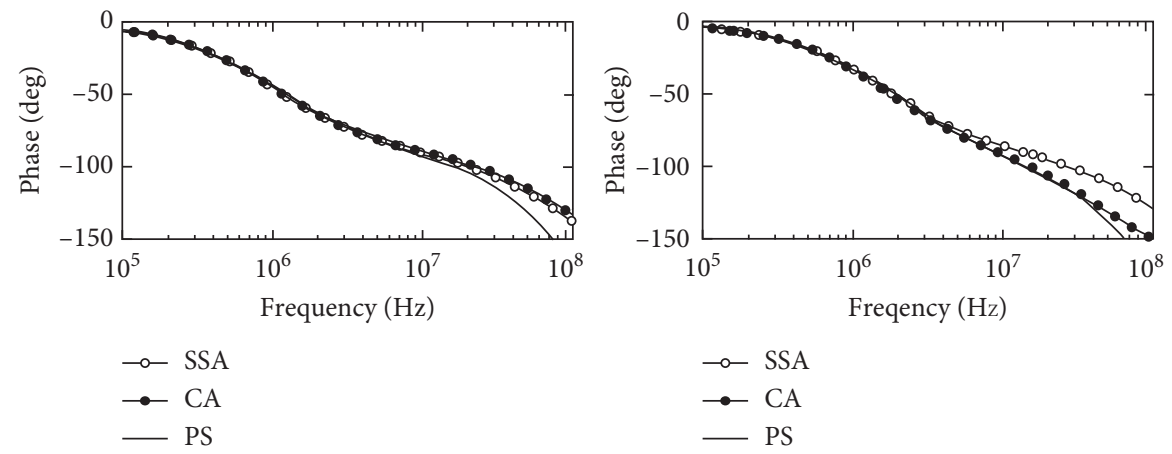

FiguRE 10: Simulation verification with the buck converter $\left(V_{\mathrm{i}}=1.2 \mathrm{~V}, f_{\mathrm{s}}=100 \mathrm{MHz}, C=10 \mathrm{nF}, L=40 \mathrm{nH}\right.$, and $\left.R=40 \Omega\right)$ : (a) $d_{1}=0.2$, $\left(2 M /\left(d_{1} T_{\mathrm{s}}(1-M)\right)\right)<\left(\left(2 M^{2}\right) /\left(d_{1}^{2} T_{\mathrm{s}}\right)\right) ;$ and $(\mathrm{b}) d_{1}=0.5,\left(2 M /\left(d_{1} T_{\mathrm{s}}(1-M)\right)\right)>\left(\left(2 M^{2}\right) /\left(d_{1}^{2} T_{\mathrm{s}}\right)\right)$.
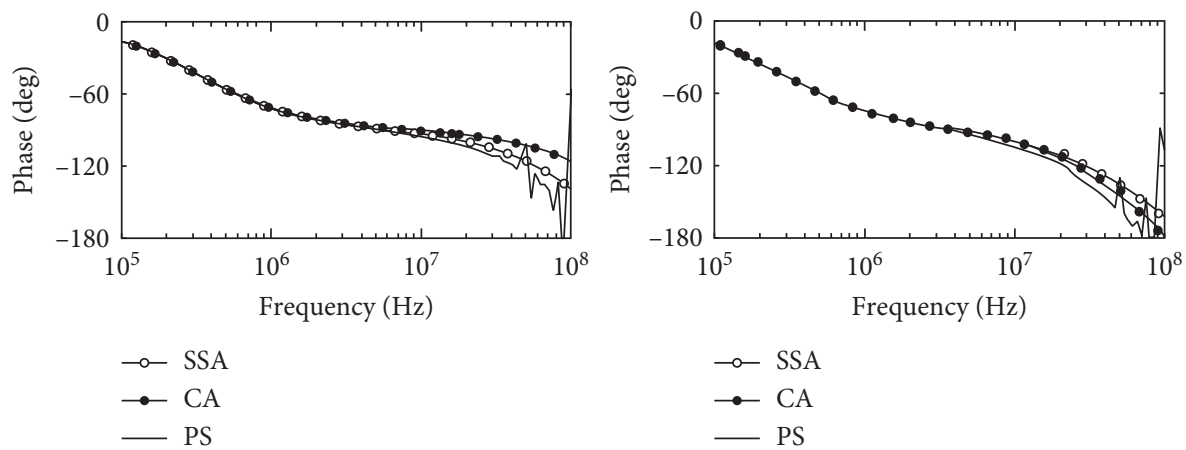

Figure 11: Simulation verification with the boost converter $\left(V_{\mathrm{i}}=1.2 \mathrm{~V}, f_{\mathrm{s}}=100 \mathrm{MHz}, C=20 \mathrm{nF}, L=2 \mathrm{nH}\right.$, and $\left.R=15 \Omega\right)$ : (a) $d_{1}=0.2$, $\min \left(\left((2(M-1)) /\left(d_{1} T_{s}\right)\right),\left(2 / d_{1} T_{s}\right)\right)<\left(2((M-1) / M)^{2} /\left(d_{1}^{2} T_{s}\right)\right)$; and $(\mathrm{b}) d_{1}=0.5, \min \left(\left((2(M-1)) /\left(d_{1} T_{s}\right)\right),\left(2 / d_{1} T_{s}\right)\right)>\left(2((M-1) / M)^{2} /\right.$ $\left.\left(d_{1}^{2} T_{s}\right)\right)$. 

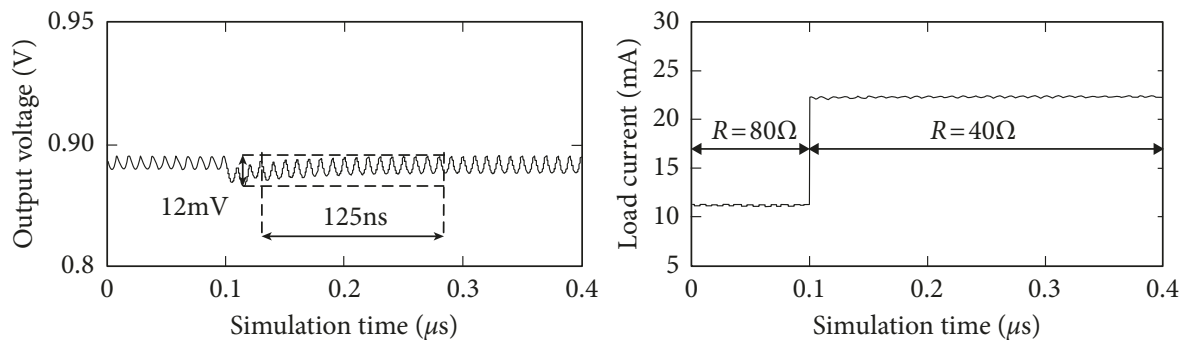

(a)
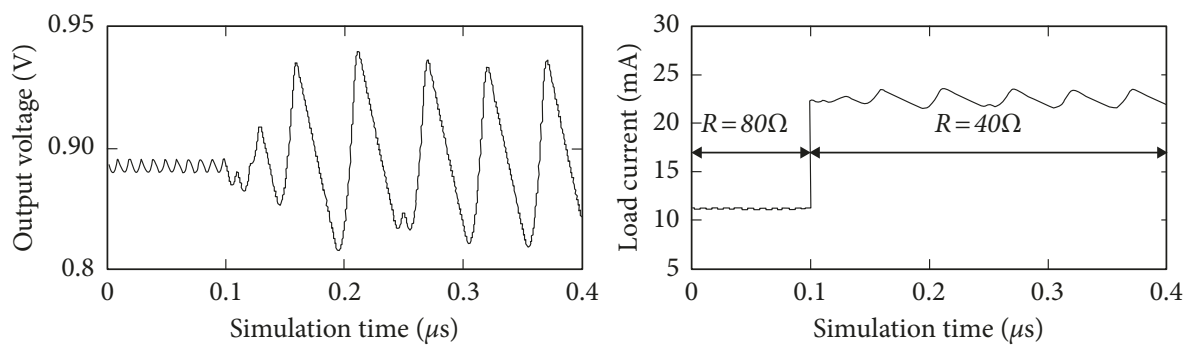

(b)

Figure 12: $V_{\mathrm{o}}$ and $i_{\mathrm{o}}$ of the designed buck converter with $\left((2 M) /\left(d_{1} T_{\mathrm{s}}(1-M)\right)\right)>\left(2 \mathrm{M}^{2} / d_{1}^{2} T_{\mathrm{s}}\right)\left(V_{\mathrm{i}}=1.2 \mathrm{~V}, f_{\mathrm{s}}=100 \mathrm{MHz}, C=10 \mathrm{nF}, L=\right.$ $40 \mathrm{nH}$, and $R=80 / 40 \Omega$ ) and $\mathrm{PM}=45^{\circ}$. (a) Compensator based on CA. (b) Compensator based on SSA.
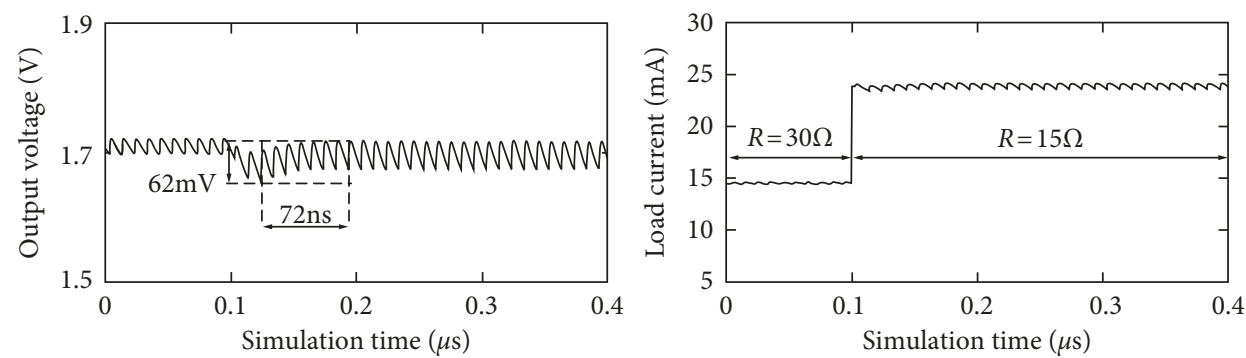

(a)
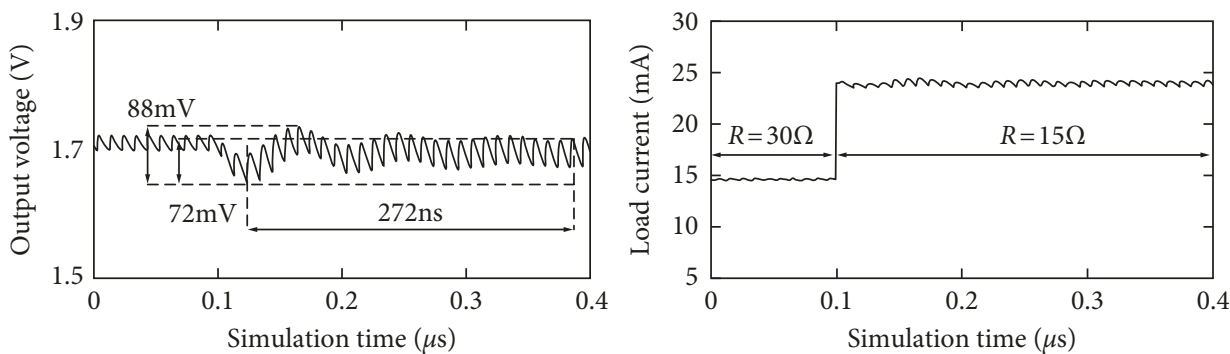

(b)

Figure 13: $V_{\mathrm{o}}$ and $i_{\mathrm{o}}$ of the designed boost converter with $\min \left(\left((2(M-1)) /\left(d_{1} T_{\mathrm{s}}\right)\right),\left(2 / d_{1} T_{\mathrm{s}}\right)\right)<\left(2((M-1) / M)^{2} /\left(d_{1}^{2} T_{\mathrm{s}}\right)\right)\left(V_{\mathrm{i}}=1.2 \mathrm{~V}, f_{\mathrm{s}}=\right.$ $100 \mathrm{MHz}, C=20 \mathrm{nF}, L=2 \mathrm{nH}$, and $R=30 / 15 \Omega$ ) and $\mathrm{PM}=45^{\circ}$. (a) Compensator based on SSA. (b) Compensator based on CA.

Figures 10-13. These figures confirm the correctness of the proposed selection strategy in Table 5 .

Figure 12 presents the simulated output voltage $V_{\mathrm{o}}$ and load current $i_{\mathrm{o}}$ of the designed closed-loop controlled buck converter during a load transient, applying a Type II compensator. As indicated in Table 5, the CA method is more accurate with the condition $\left((2 M) /\left(d_{1} T_{\mathrm{s}}(1-M)\right)\right)>$ $\left(\left(2 M^{2}\right) /\left(d_{1}^{2} T_{s}\right)\right)$, and the simulated result (Figure 12) also confirms that the closed-loop controller designed with the CA method exhibits better stability and transient response than the SSA method, even though both cases have the same phase margin (PM) of $45^{\circ}$. On the other hand, Figure 13 shows the simulated $V_{\mathrm{o}}$ and the $i_{\mathrm{o}}$ of the closedloop controlled boost converter during a load transient, applying also a Type II compensator. In this case, as indicated in Table 5, the SSA modeling method is more accurate with the condition $\left(\min \left((2(M-1)) /\left(d_{1} T_{\mathrm{s}}\right)\right),(2 /\right.$ $\left.\left.d_{1} T_{\mathrm{s}}\right)\right)<\left(\left(2((M-1) / M)^{2}\right) /\left(d_{1}^{2} T_{\mathrm{s}}\right)\right)$ and the simulated result 
(Figure 13) also confirms that the closed-loop controller designed with SSA method obtain a better stability and transient response. When there is a sudden change of the $i_{\mathrm{o}}$, the boost converter with the SSA method responds faster than that with the CA method.

Unlike the conclusion made in [6], this paper shows that, in some cases, the CA method exhibits better accuracy than the SSA method. Figures 12 and 13 confirm that an accurate modeling method is critical to design the appropriate closedloop controller of the DC-DC converter, demonstrating that the selection strategy given in Table 5 is essential and necessary in the design. The general and streamlined small signal deduction process for both modeling methods can be further applied conveniently to similar DC-DC converter topologies.

\section{Conclusions}

This paper presented the review, study, DCM small signal modeling deduction and simulation verification by using the improved SSA and CA methods for four DC-DC converters. This paper first proposed a general and intuitive deriving process for the improved SSA and CA modeling methods, such that the corresponding DCM small signal models for DC-DC converters can be easily determined. Then, this paper discovers that the CA can obtain higher accuracy than the improved SSA at some operating conditions, as some research studies claimed that the improved SSA can obtain the highest accuracy among all the modeling methods. Finally, this paper provided a selection strategy for a highaccuracy modeling method for various DC-DC converters operating in DCM, verified by simulations, which is necessary and beneficial in the design of a more accurate DCM closed-loop controller for DC-DC converters, achieving better stability and transient response.

\section{Conflicts of Interest}

The authors declare that there are no conflicts of interest regarding the publication of this paper.

\section{Acknowledgments}

This work was supported in part by the Science and Technology Development Fund, Macao SAR (FDCT) (120/2016/A3) and in part by the Research Committee of the University of Macau (MYRG2015-00030-AMSV and MYRG2017-00090-AMSV).

\section{References}

[1] R. D. Middlebrook and S. Cuk, "A general unified approach to modelling switching-converter power stages," in Proceedings of IEEE Annual Power Electronics Specialists Conference (PESC), pp. 18-34, Cleveland, OH, USA, 1976.

[2] R. Tymerski and V. Vorperian, "Generation, classification and analysis of switched-mode DC-to-DC converters by the use of converter cells," in Proceedings of International Telecommunications Energy Conference, pp. 181-195, Toronto, Canada, 1986.
[3] D. Maksimovic and S. Cuk, "A unified analysis of PWM converters in discontinuous modes," IEEE Transactions on Power Electronics, vol. 6, no. 3, pp. 476-490, 1991.

[4] E. Mamarelis, G. Petrone, and G. Spagnuolo, "An hybrid digital-analog sliding mode controller for photovoltaic applications," IEEE Transactions on Industrial Informatics, vol. 9, no. 2, pp. 1094-1103, 2013.

[5] V. Vorperian, "Simplified analysis of PWM converters using model of PWM switch. II. Discontinuous conduction mode," IEEE Transactions on Aerospace and Electronic Systems, vol. 26, no. 3, pp. 497-505, 1990.

[6] J. Sun, D. M. Mitchell, M. F. Greuel, P. T. Krein, and R. M. Bass, "Averaged modeling of PWM converters operating in discontinuous conduction mode," IEEE Transactions on Power Electronics, vol. 16, no. 4, pp. 482-492, 2001.

[7] K. Mandal, S. Banerjee, and C. Chakraborty, "A new algorithm for small-signal analysis of DC-DC converters," IEEE Transactions on Industrial Informatics, vol. 10, no. 1, pp. 628-636, 2014.

[8] R. H. G. Tan and M. Y. W. Teow, "A comprehensive modeling, simulation and computational implementation of buck converter using MATLAB/Simulink," in Proceedings of IEEE Conference on Energy Conversion, pp. 37-42, Johor Bahru, Malaysia, 2014.

[9] J. P. Torreglosa, P. García, L. M. Fernández, and F. Jurado, "Predictive control for the energy management of a fuelcell-battery-supercapacitor tramway," IEEE Transactions on Industrial Informatics, vol. 10, no. 1, pp. 276-285, 2014.

[10] M. K. Kazimierczuk, Pulse-Width Modulated DC-DC Power Converters, Wiley, West Sussex, UK, 2008.

[11] J. Sun, D. M. Mitchell, M. F. Greuel, P. T. Krein, and R. M. Bass, "Modeling of PWM converters in discontinuous conduction mode. A reexamination," in Proceedings of IEEE Annual Power Electronics Specialists Conference (PESC), pp. 615-622, Fukuoka, Japan, 1998.

[12] W. R. Liou, W. B. Lacorte, A. B. Caberos et al., "A programmable controller IC for DC/DC converter and power factor correction applications," IEEE Transactions on Industrial Informatics, vol. 9, no. 4, pp. 2105-2113, 2013.

[13] W. L. Zeng, C.-S. Lam, W.-M. Zheng et al., "DCM operation analysis of ky converter," Electronics Letters, vol. 51, no. 24, pp. 2037-2039, 2015.

[14] Y. Qiu, X. Y. Chen, C. Q. Zhong, and C. Qi, "Uniform models of PWM DC-DC converters for discontinuous conduction mode considering parasitics," IEEE Transactions on Industrial Electronics, vol. 61, no. 11, pp. 6071-6080, 2014.

[15] A. Davoudi, J. Jatskevich, and T. De Rybel, "Numerical statespace average-value modeling of PWM DC-DC converters operating in DCM and CCM," IEEE Transactions on Power Electronics, vol. 21, no. 4, pp. 1003-1012, 2006.

[16] M. U. Iftikhar, P. Lefranc, D. Sadarnac, and C. Karimi, "Theoretical and experimental investigation of averaged modeling of non-ideal PWM DC-DC converters operating in DCM," in Proceedings of IEEE Annual Power Electronics Specialists Conference (PESC), pp. 2257-2263, Rhodes, Greece, 2008.

[17] R. Trinchero, I. S. Stievano, and F. G. Canavero, "Steady-state analysis of switching power converters via augmented timeinvariant equivalents," IEEE Transactions on Power Electronics, vol. 29, no. 11, pp. 5657-5661, 2014.

[18] T. Pavlovic, T. Bjazic, and Z. Ban, "Simplified averaged models of DC-DC power converters suitable for controller design and microgrid simulation," IEEE Transactions on Power Electronics, vol. 28, no. 7, pp. 3266-3276, 2013. 
[19] E. Van Dijk, J. N. Spruijt, D. M. O'Sullivan, and J. B. Klaassens, "PWM-switch modeling of DC-DC converters," IEEE Transactions on Power Electronics, vol. 10, no. 6, pp. 659-665, 1995.

[20] C. P. Basso, Switch-Mode Power Supplies, McGraw-Hill, New York, NY, USA, 2008.

[21] R. W. Erickson and D. Maksimovic, Fundamentals of Power Electronics, Kluwer Academic Publisher, Norwell, MA, USA, 2001.

[22] G. Nirgude, R. Tirumala, and N. Mohan, “A new, large-signal average model for single-switch DC-DC converters operating in both CCM and DCM," in Proceedings of IEEE Annual Power Electronics Specialists Conference (PESC), vol. 3, pp. 1736-1741, Vancouver, BC, Canada, 2001.

[23] K. I. Hwu and Y. T. Yau, "KY converter and its derivatives," IEEE Transactions on Power Electronics, vol. 24, no. 1, pp. 128-137, 2009. 


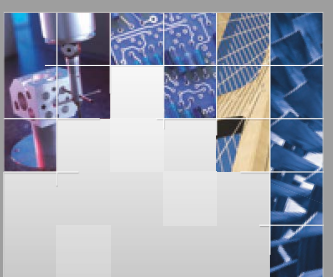

\section{Enfincering}
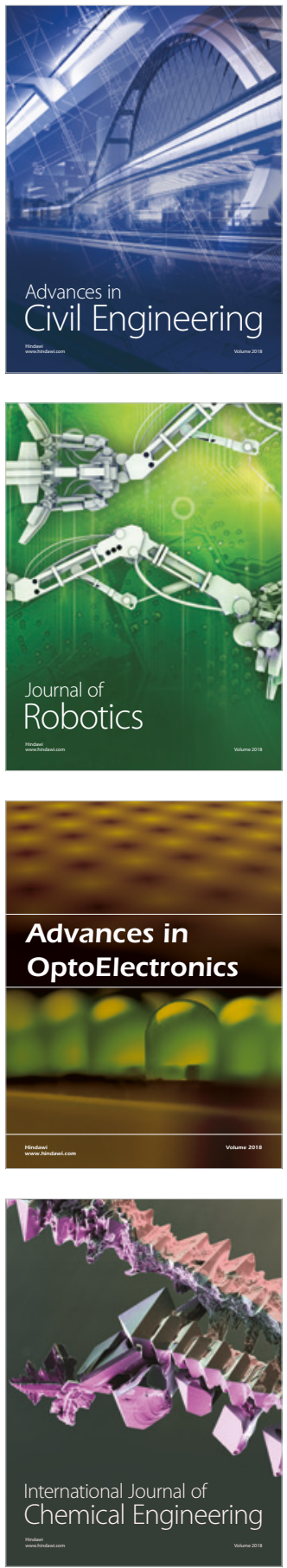

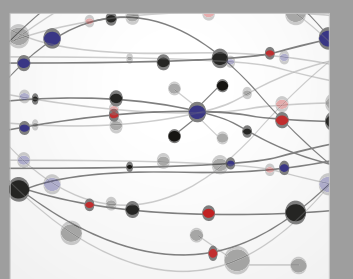

\section{Rotating \\ Machinery}

The Scientific World Journal

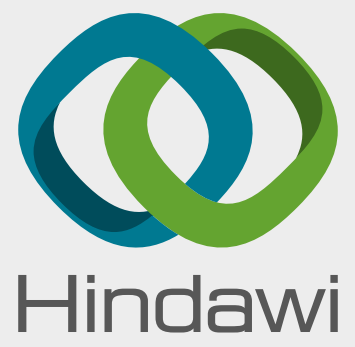

Submit your manuscripts at

www.hindawi.com
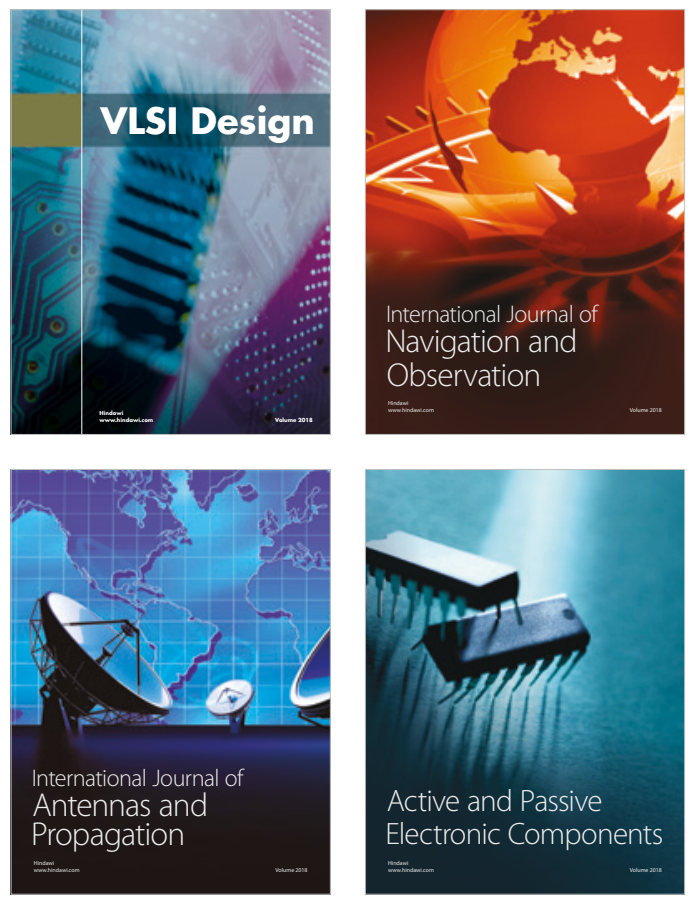
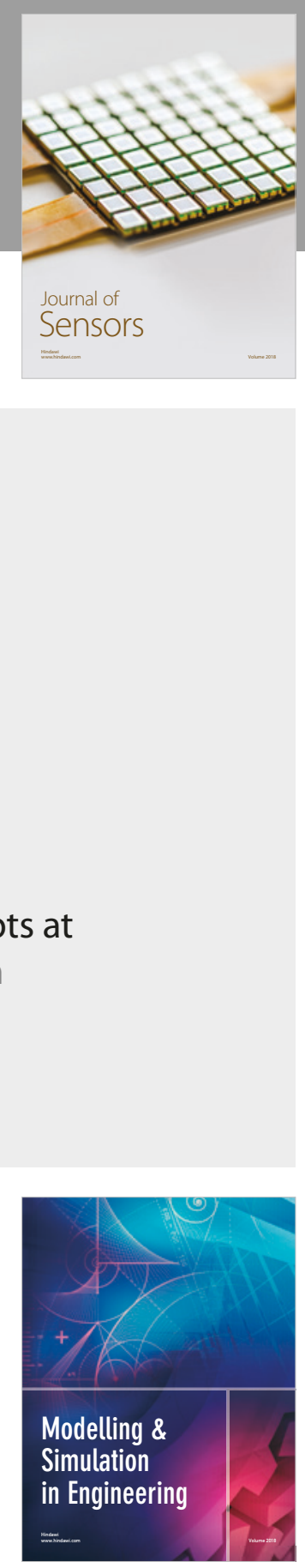

\section{Advances \\ Multimedia}
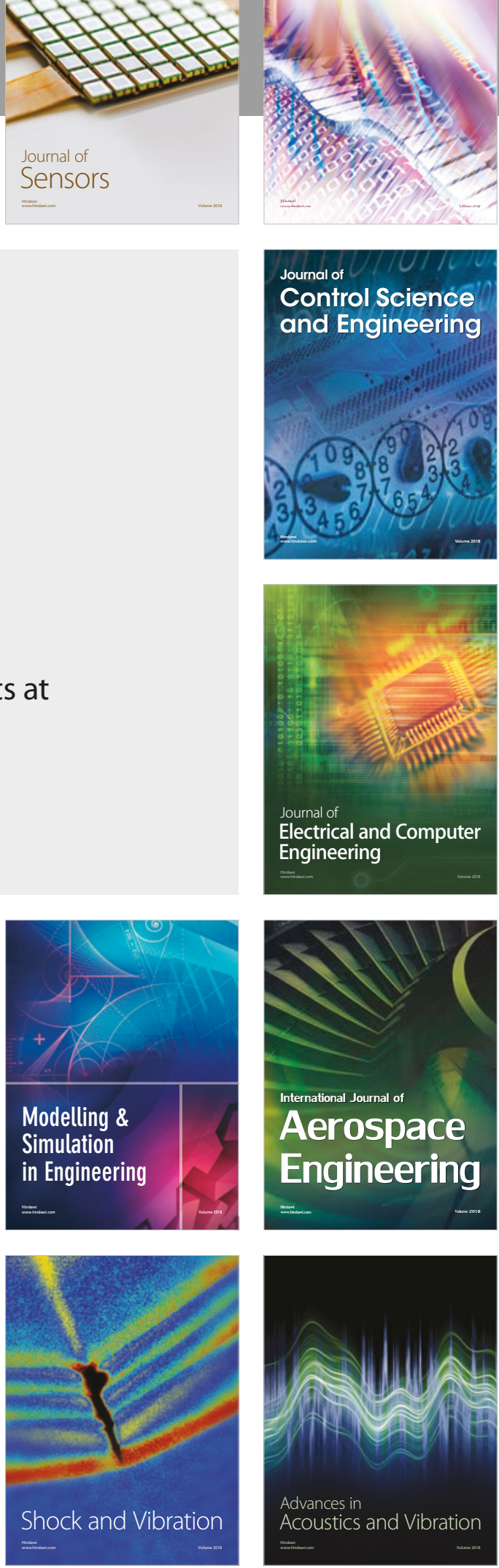